\title{
Dopingfree Schottky Buried Metal Layer Fully Depleted Planar FET for SCE Suppression at sub- 28nm Technology Nodes
}

Nawaz Shafi

MNIT Jaipur: Malaviya National Institute of Technology

Aasif Mohammad Bhat ( 2018 rec9057@mnit.ac.in )

Malaviya National Institute of Technology https://orcid.org/0000-0003-4767-9885

Jaydeep Singh Parmaar

MNIT Jaipur: Malaviya National Institute of Technology

Ankita Porwal

MNIT Jaipur: Malaviya National Institute of Technology

Chitrakant Sahu

MNIT Jaipur: Malaviya National Institute of Technology

C. Periasamy

MNIT Jaipur: Malaviya National Institute of Technology

\section{Research Article}

Keywords: Buried metal layer (BML) , Charge plasma , Dopingfree, Junctionless field effect transistor (FET) , Scaling , SCEs (short channel effects), Workfunction

Posted Date: April 12th, 2021

DOl: https://doi.org/10.21203/rs.3.rs-347778/v1

License: (c) (1) This work is licensed under a Creative Commons Attribution 4.0 International License.

Read Full License 


\title{
Dopingfree Schottky Buried Metal Layer Fully Depleted Planar FET for SCE Suppression at sub-28nm Technology Nodes
}

\author{
Design, Simulation and Performance Investigation
}

\author{
Nawaz Shafi • Aasif Mohammad Bhat • Jaydeep Singh Parmaar • \\ Ankita Porwal · Chitrakant Sahu • C. Periasamy
}

Received: date / Accepted: date

\begin{abstract}
Herein we introduce and investigate a new architectural design strategy for planar single gate field effect transistors (SG-FETs) that delivers advantages from all fronts of design, fabrication and performance perspectives. The amalgamation of schottky buried metal layer (BML) and charge plasma (CP) mechanism of doping in planar single gate architecture yields a novel type of FET called as CP-BML FET. Owing to the schottky BML induced depletion region created on the bottom side of device layer reduces effective device layer thickness $\left(\mathrm{T}_{\mathrm{Si}}\right)$ suppressing short channel effects (SCEs) including drain induced barrier lowering (DIBL) and threshold voltage roll-off. The proposed FET has been analyzed for DC and RF performance figure of merits (FOMs) and compared to counter part state of the art technologies with reference to ITRS performance projections. The proposed FET is also investigated the performance FOMs on for criticality of physical parameters including gate length $\left(\mathrm{L}_{\mathrm{g}}\right)$, device layer thickness $\left(\mathrm{T}_{\mathrm{Si}}\right)$, BML workfunction $\left(\phi_{\mathrm{BML}}\right)$. The $\mathrm{I}_{\mathrm{ON}}$ and $\mathrm{I}_{\mathrm{OFF}}$ for proposed device at $\mathrm{L}_{\mathrm{g}}=20 \mathrm{~nm}$ read at $730 \mu \mathrm{A} / \mu \mathrm{m}$ and $7 \times 10^{-2} \mathrm{pA} / \mu \mathrm{m}$ respectively. $\mathrm{RF}$ performance analysis reveal transition frequency $\left(\mathrm{f}_{\mathrm{t}}\right)$ of $390 \mathrm{GHz}$ with SS $\simeq 75 \mathrm{mV} / \mathrm{dec}$ coherent with ITRS performance projections. It is found that ultra scaled $(7 \mathrm{~nm})$ proposed device exhibits intrinsic delay $\tau$ of $0.6 \mathrm{ps}$ which is superior to ITRS projections of $1.71 \mathrm{ps}$ at $28 \mathrm{~nm}$ technology node. The proposed device yields $\mathrm{P}_{\mathrm{dyn}}$ of $0.248 \mathrm{fJ} / \mu \mathrm{m}$ at $\mathrm{L}_{\mathrm{g}}=7 \mathrm{~nm}$ implicating it to be potential candidate for low power with high performance application requirements.
\end{abstract}

Department of Electronics and Communucation Engineering Malaviya National Institute of Technology Jaipur

Rajasthan-302017, India

E-mail: 2017rec9021@mnit.ac.in
Keywords Buried metal layer (BML) - Charge plasma - Dopingfree · Junctionless field effect transistor (FET) · Scaling · SCEs (short channel effects) · Workfunction.

\section{Introduction}

The progress in semiconductor device technology imposes physical limits on scaling that renders adhesion to Moore's law. Following Moore's law, the incessant scaling of classical CMOS (complementary metal oxide semiconductor) technology transistor is accompanied by short geometry effects (SCEs) [1]. With scaling of gate length $\left(\mathrm{L}_{\mathrm{g}}\right)$, SCEs hold a critical role in determining the performance of transistors especially for RF applications. For technology nodes below $28 \mathrm{~nm}$, classical CMOS approach fails to live upto the minimum requirements of various performance metrics that include OFF state current $\left(\mathrm{I}_{\mathrm{Off}}\right)$, subthreshold swing $(\mathrm{SS}), \frac{\mathrm{I}_{\mathrm{On}}}{\mathrm{I}_{\mathrm{Off}}}$ ratio, drain induced barrier lowering (DIBL), transition frequency $\left(f_{t}\right)$, power dissipation [2]. Sub-22 nm technology nodes suffer heavily with limitations of perfect abrupt doping profiles which in-turn yields in performance that does not comply with international technology roadmap of semiconductors (ITRS) projections [3]. Already several technologies different from conventional CMOS have been implemented at industry level that comply with ITRS standards like FinFETs, multigate FETs, junctionless FETs etc [4].

Scaling has been classified on time scale as geometrical scaling (1975-2002: proportional scaling down of geometrical dimensions for planar architectures), equivalent scaling (2003-2025: down scaling of only horizontal feature size $\left.\left(\mathrm{L}_{\mathrm{g}}\right)\right)$ and 3D power scaling (2025-2040: vertical device architectures) [5]. The current era of 
equivalent scaling paves the way for introduction of new materials along with exploration of physical effects for new device architectures whilst maintaining ITRS performance projections [6]. ITRS 2026 projects the the maximum $\mathrm{I}_{\mathrm{OFF}}$ of $5 \mathrm{nA} / \mu \mathrm{m}, \mathrm{I}_{\mathrm{ON}}$ of $0.6 \mathrm{~mA} / \mu \mathrm{m}$, intrinsic gate delay of $0.26 \mathrm{ps}$ for low operating power devices [7]. Various architectural modifications exploring new realms of device physics have been proposed in the last decade. One of such techniques is the junctionless transistor (JLT) where the depletion in the channel is induced by the gate workfunction engineering in the OFF-state [8]. The channel of JLT consists of uniform high doping throughout source-channel-drain regions eliminating the requirement of abrupt/steep junction doping profiles $[9,10]$. However this device kind of architecture is not fruitful in single planar structures where efficient volume depletion is not achieved $[11,12]$. Moreover due to high doping requirements typically of the order of $10^{19} \mathrm{~cm}^{-3}$, the device fabrication requires high thermal budget with complex ion implantation process which become even more tedious at lower technology nodes [11].

The concept of virtual doping against the conventional chemical doping technique is imbibed from the concept of contact electrode workfunction engineering called charge plasma engineering that induces high density charge carriers in intrinsic semiconductors using electrodes of appropriate workfunction [13]. This provides the relaxation from requirement of high doping whilst maintaining high $\mathrm{I}_{\mathrm{ON}}$ and low $\mathrm{I}_{\mathrm{OFF}}[14,15] \mathrm{In}$ single gate planar device architectures, introduction of buried metal layer (BML) with realization of schottky junction at the bottom side provides superior depletion limiting OFF-state current [16]. The amalgamation of charge plasma engineering with BML in planar device architectures provides window for equivalent scaling whilst meeting the ITRS performance requirements even upto $7 \mathrm{~nm}$ technology node.

Deliverables and Organization of this work

In this work, we propose a new geometrically planar field effect transistor with a single gate controlled channel delivering the performance compared to that of multigate FETs more importantly following ITRS requirements. The proposed device exhaustively uses the geometrical advantages of SOI FETs delivers a superior FET when designed in conjuncture with charge plasma technique relieving the fabrication scheme from high budget doping process. The use of Schottky buried metal layer realizes complete depletion of the channel limiting Off-state current to minimum eliminating one of the main liabilities of single gate planar architecture FETs. The report is organized as, in Section 2, the device architectural specifications along with parameters for experimental calibration are discussed. The proposed device is analyzed for DC as well as RF conditions presented in Section 3. The performance is compared to state of art devices given in Section 3.4. The overall performance of the proposed device is at par with the requirements by ITRS considerations.
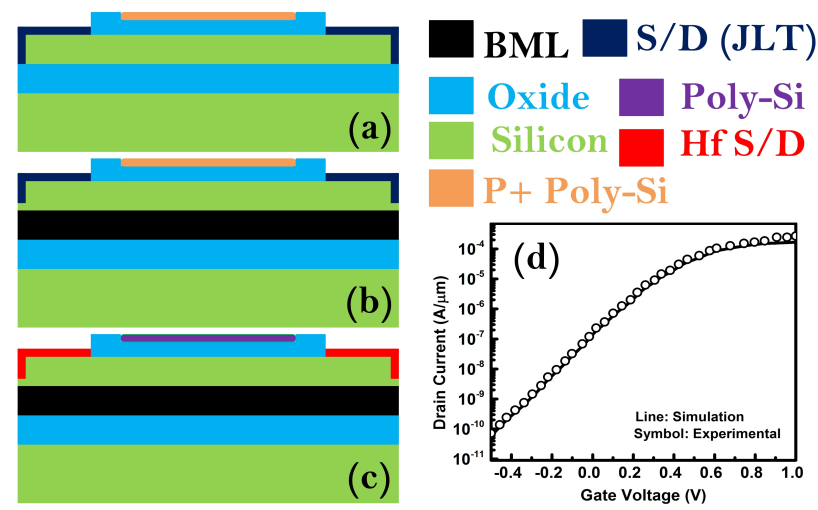

Fig. 1 (a) Conventional bulk planar junctionless SOI FET [17], (b) Bulk planar junctionless with buried metal layer FET, (c) Proposed charge plasma induced dopingless source drain fully depleted buried metal layer planar FET (d) Experimental calibration of simulation model for BP-JLT with [17].

\section{Device Architectural Specs, Simulation Methodology and Experimental Calibration}

Figure 1 (a-c) shows the device architectural variations from schematics in the conventional bulk planar junctionless SOI FET, the bulk planar junctionless with buried metal layer SOI FET and the proposed FET with schottky BML where the source and drain regions are realized by charge plasma concept of virtual doping. Table 1 lists all the physical parameter specifications of the proposed and compared counterpart device. High doping concentration of $10^{19} \mathrm{~cm}^{-2}$ throughout source, channel and drain regions in the junctionless FET ensures high On-state current where as the gate workfunction $\left(\phi_{\mathrm{G}}\right)$ is chosen such the complete depletion is attained in Off-state ensuring sufficient $\frac{\mathrm{I}_{\text {On }}}{\mathrm{I}_{\text {Off }}}$ ratio. For single gate conventional MOS devices, the gate control on the channel is feeble and the extent of which is limited into the channel depth. This leads to enhanced $\mathrm{I}_{\mathrm{Off}}$, thereby limiting the power consumption performance of the device. The inception of schottky buried metal layer (BML) is to virtually reduce the effective device layer thickness in single gate devices to enhance the gate control on the channel by creating a space charge region with no mobile ions on the bottom side of device layer. 
Table 1 Physical parameter specification of junctionless buried metal layer FET (JL-BML-FET) and proposed charge plasma dopingless buried metal layer FET (CP-BML-FET).

\begin{tabular}{|l|c|c|}
\hline \hline Parameter (Symbol) & JL-BML-FET & CP-BML-FET \\
\hline \hline Gate Length $\left(\mathrm{L}_{\mathrm{G}}\right)$ & $20 \mathrm{~nm}$ & $20 \mathrm{~nm}$ \\
Drain Length $\left(\mathrm{L}_{\mathrm{D}}\right)$ & $20 \mathrm{~nm}$ & $20 \mathrm{~nm}$ \\
Source Length $\left(\mathrm{L}_{\mathrm{S}}\right)$ & $20 \mathrm{~nm}$ & $20 \mathrm{~nm}$ \\
Buried Oxide Thickness $\left(\mathrm{T}_{\mathrm{Box}}\right)$ & $50 \mathrm{~nm}$ & $50 \mathrm{~nm}$ \\
Effective gate Oxide Thickness $\left(\mathrm{T}_{\mathrm{ox}}\right)$ & $0.8 \mathrm{~nm}$ & $0.8 \mathrm{~nm}$ \\
Device Layer Thickness $\left(\mathrm{T}_{\mathrm{Si}}\right)$ & $10 \mathrm{~nm}$ & $10 \mathrm{~nm}$ \\
Gate Workfunction $\left(\phi_{\mathrm{G}}\right)$ & $5.12 \mathrm{eV}$ & $4.12 \mathrm{eV} \mathrm{nm}$ \\
Source/Drain contact Workfunction $\left(\phi_{\mathrm{M}}\right)$ & $4.12 \mathrm{eV}$ & $3.9 \mathrm{eV} \mathrm{nm}$ \\
Doping Concentration Device Layer $\left(\mathrm{N}_{\mathrm{D}}\right)$ & $10^{19} \mathrm{~cm}^{-2}$ & $10^{16} \mathrm{~cm}^{-2}$ \\
Buried Metal Layer Workfunction $\left(\phi_{\mathrm{BML}}\right)$ & $5.2 \mathrm{eV}$ & $5.2 \mathrm{eV}$ \\
\hline \hline
\end{tabular}

A sufficient schottky barrier height $\left(\phi_{\mathrm{BH}}\right)$ ensures the formation of depletion region, the depth of which is a function of workfunction of buried metal layer $\left(\phi_{\mathrm{BML}}\right)$. The extent of depletion region by schottky BML is given by Eq. 1.

$\mathrm{y}_{\mathrm{dep}, \mathrm{BML}}=\sqrt{\frac{2 \epsilon_{\mathrm{Si}}}{\mathrm{q} N_{\mathrm{D}}}\left\{\mathrm{q}\left(\phi_{\mathrm{BML}}-\phi_{\mathrm{Si}}\right)-\mathrm{V}_{\mathrm{T}}-\mathrm{V}_{\mathrm{BML}}\right\}}$

In above Eq. 1, $\epsilon_{\mathrm{Si}}, \mathrm{N}_{\mathrm{D}}, \mathrm{q}, \phi_{\mathrm{Si}}, \mathrm{V}_{\mathrm{T}}, \mathrm{V}_{\mathrm{BML}}$ represent permittivity of silicon, device layer doping concentration, electron affinity of silicon, thermal voltage and voltage applied at buried metal layer. As indicative in the equation, for higher doping concentrations, the workfunction of BML to effectively create the depletion region, BML with high workfunction is required which may not be feasible. The workfunction of BML is chosen such that $\phi_{\mathrm{BML}}-\phi_{\mathrm{Si}}>0$, where $\phi_{\mathrm{Si}}=\chi_{\mathrm{Si}}+$ $\frac{E_{G}}{2}+\frac{K T}{q} \ln \frac{N_{D}}{N_{i}}$. Since the inception of minimization of semiconductor devices, chemical doping and associated annealing procedures pose challenge to scaling of technology [6]. The doping and annealing processes are essentially carried out in high temperatures not only increasing the thermal budget but may render the device useless at small technology nodes by oxidation and uncontrolled ion activation [10]. The formation of high carrier concentration regions in moderately intrinsic device layer by workfunction engineering of contact electrodes forbids the use of chemical doping and annealing techniques in the fabrication process $[15,18]$. The formation of charge plasma (electron or hole plasma) in the semiconductor depends on following two essential conditions:

1) For electron plasma formation, $\phi_{\mathrm{S} / \mathrm{D}}>\left(\chi_{\mathrm{Si}}+\right.$ $\left.\frac{\mathrm{E}_{\mathrm{G}, \mathrm{Si}}}{2}\right)$. To form the hole plasma, $\phi_{\mathrm{S} / \mathrm{D}}<\left(\chi_{\mathrm{Si}}+\frac{\mathrm{E}_{\mathrm{G}, \mathrm{Si}}}{2}\right)$ $[14,19]$. In this work hafnium with workfunction of 3.9 $\mathrm{eV}$ have been used as source and drain contact electrodes creating electron plasma in moderately intrinsic semiconductor. 2) The thickness of the semiconductor layer $\left(\mathrm{t}_{\mathrm{Si}}\right)$ must be less than Debye's length
$\left(\lambda_{\mathrm{D}}=\sqrt{\frac{\epsilon_{\mathrm{Si}} V_{\mathrm{T}}}{\mathrm{q} N_{\mathrm{D}}}}\right)$. For every $\lambda_{\mathrm{D}}$ addition to $\mathrm{t}_{\mathrm{Si}}$, the electric field by contact electrode is screened by $\frac{1}{\mathrm{e}}[13]$.

\subsection{Simulation Framework and Experimental Calibration}

For credible and reliable simulation results, various models have been invoked in Atlas Silvaco collectively. The different in-built models invoked during the simulations account for different carrier transport phenomena. Highly doped devices are prone to bandgap narrowing where the change in energy bandgap $\left(\triangle \mathrm{E}_{\mathrm{G}}\right)$ becomes doping concentration dependent which in turn affects the electron affinity $(\chi)$ of the material, such effects are simulated by invoking BGN model in the simulator. Prior to BGN it is important to consider the carrier transport physics which is taken care by FERMI-DIRAC model which solves Boltzmann's-Fermi Dirac statistics for charge carriers with different energy levels. ShockleyRead-Hall (SRH) and AUGER models for recombination are also included in the simulation framework. Bulk planar junctionless FET (BP-JLT) has been reproduced and the parameters which include energy band density of states (NC300, NV300), carrier lifetimes (electron lifetime: TAUN0, hole lifetime: TAUP0), interface charges, in simulation model have been adjusted to achieve the experimental characteristics of BP-JLT in [17] as shown in Fig. $1(\mathrm{~d})$. The carrier life times $\left(\tau_{\mathrm{p}}, \tau_{\mathrm{n}}\right)$ were set to be $10^{-1} \mu \mathrm{s}$. The energy band density of states $\left(\mathrm{N}_{\mathrm{C}}, \mathrm{N}_{\mathrm{V}}\right)$ at $300^{\circ} \mathrm{K}$ are taken as $2.8 \times 10^{19} \mathrm{~cm}^{-3}$ and $1.04 \times 10^{19} \mathrm{~cm}^{-3}$ respectively. The electron and hole thermal velocities $\left(\mathrm{V}_{\mathrm{n}}, \mathrm{V}_{\mathrm{p}}\right)$ were set to be $1.08 \times 10^{7} \mathrm{~cm} / \mathrm{s}$ and $1.3 \times 10^{7} \mathrm{~cm} / \mathrm{s}$ respectively considering saturation velocities to be equal.

\section{Simulation Results and Discussion}

The performance metrics for the proposed charge plasma BML FET under for DC and AC conditions have been 
evaluated and extensively studied for dependence in physical parameters that include scaling $\left(\mathrm{L}_{\mathrm{g}}\right)$, BML workfunction $\left(\phi_{\mathrm{BML}}\right)$, device layer thickness $\left(\mathrm{t}_{\mathrm{Si}}\right)$. On the basis of performance metrics that include DIBL, $\mathrm{I}_{\mathrm{ON}}, \mathrm{I}_{\mathrm{OFF}} \mathrm{I}_{\mathrm{ON}} / \mathrm{I}_{\mathrm{OFF}}$, SS, transconductance $\left(\mathrm{g}_{\mathrm{m}}\right)$, output conductance $\left(\mathrm{g}_{\mathrm{d}}\right), \mathrm{C}_{\mathrm{gs}}, \mathrm{C}_{\mathrm{gd}}, \mathrm{f}_{\mathrm{t}}, \mathrm{f}_{\max }, \mathrm{GBP}, \mathrm{A}_{\mathrm{V}}$, TGF, TFP, $\tau$, and $\mathrm{P}_{\mathrm{dyn}}$, the performance of proposed device has been compared with counterpart technologies particularly at sub-28nm technology nodes.

\subsection{Performance Analysis}
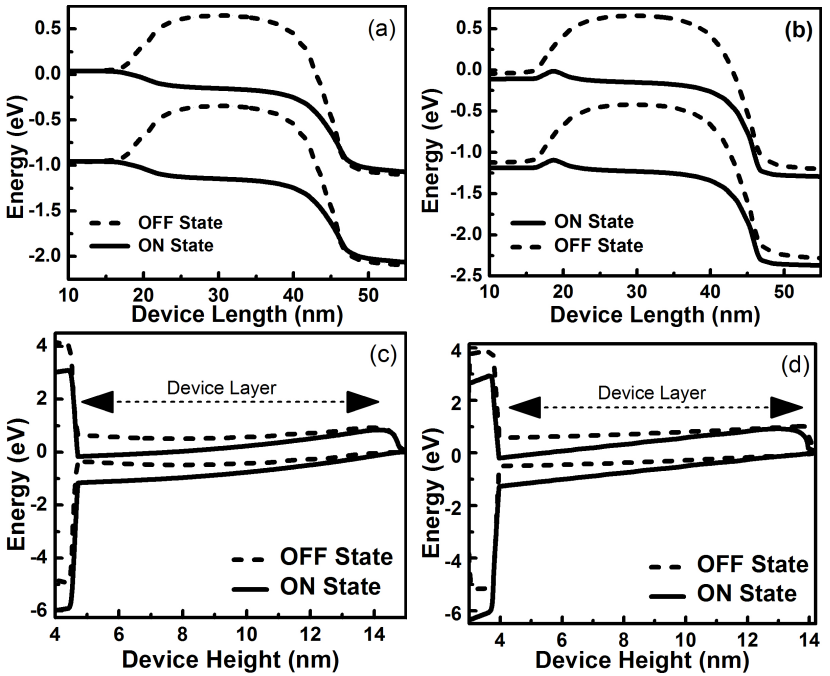

Fig. 2 (a). Horizontal energy band variation for JL-BMLSOI FET in OFF and ON state, (b). Horizontal energy band variation for CP-BML-SOI FET in OFF and ON state, (c). Vertical energy band variation in channel for JL-BML-SOI FET in OFF and ON state, (d). Vertical energy band variation in channel for CP-BML-SOI FET in OFF and ON state. OFF state @ $\mathrm{V}_{\mathrm{gs}}=0 \mathrm{~V}, \mathrm{~V}_{\mathrm{ds}}=1.2 \mathrm{~V}$, ON state @ $\mathrm{V}_{\mathrm{gs}}=1.2 \mathrm{~V}, \mathrm{~V}_{\mathrm{ds}}=1.2 \mathrm{~V}$.

The horizontal and vertical variations in energy band levels for ON-state $\left(\mathrm{V}_{\mathrm{GS}}, V_{D S}=1.2 \mathrm{~V}, 1.2 \mathrm{~V}\right)$ and OFFstate $\left(V_{G S}, \mathrm{~V}_{\mathrm{DS}}=0 \mathrm{~V}, 1.2 \mathrm{~V}\right)$ for CP-BML FET and JLBML FET are shown in Fig. 2(a-d). In OFF-state there is a barrier height of $0.72 \mathrm{~V}$ for majority carriers in $\mathrm{CP}$ BML FET while as barrier height of $0.6 \mathrm{~V}$ is observed in JL-BML FET leading to enhanced gate control in former device. The horizontal energy band variations reveal the absence of tunneling path in OFF-state minimizing the OFF-state current even at 20nm technology node. The vertical energy band variation across the gate oxide and device layer are almost same except that band bending for JL-BML FET is more than CP-BML FET due to high workfunction gate $\left(\phi_{\mathrm{G}}=5.1 \mathrm{eV}\right)$ in the junctionless FET. Fig. 3(a) show the transfer characteristics for proposed CP-BML FET and JL-BML FET for $\mathrm{L}_{\mathrm{g}}=20 \mathrm{~nm}$ at $\mathrm{V}_{\mathrm{DS}}=1.2 \mathrm{~V}$. The $\mathrm{I}_{\mathrm{ON}}$ and $\mathrm{IOFF}$ for CP-BML FET read at $730 \mu \mathrm{A} / \mu \mathrm{m}$ and $7 \times 10^{-2} \mathrm{pA} / \mu \mathrm{m}$ respectively while for JL-BML FET $\mathrm{I}_{\mathrm{ON}}$ and $\mathrm{I}_{\mathrm{OFF}}$ read at $0.4 \mu \mathrm{A} / \mu \mathrm{m}$ and $0.2 \mathrm{pA} / \mu \mathrm{A}$ respectively. At $\mathrm{L}_{\mathrm{g}}=$ $20 \mathrm{~nm}$, and driving voltage $\mathrm{V}_{\mathrm{DS}}=1.2 \mathrm{~V}, \mathrm{CP}-\mathrm{BML}$ FET has superior $\frac{\text { ION }}{\mathrm{IOFF}}$ ratio of $10^{11}$ against $10^{8}$ for JL-BML FET which satisfies the ITRS 2025 requirement. The steeper SS $\left(=2.3 \mathrm{~V}_{\mathrm{T}}\left(1+\frac{\mathrm{Cdm}}{\mathrm{C}_{\mathrm{x}}}\right)\right)$ of $75 \mathrm{mV} / \mathrm{dec}$ and low OFF-state current in CP-BML FET is owed to smaller depletion capacitance $\left(\mathrm{C}_{\mathrm{dm}}\right)$, also the channel controllability of gate is firm due to weak penetration of depletion regions formed by charge plasma induced source/drain regions and depletion in device layer due to schottky BML. Figure 3(b) compares transconductance at $\mathrm{V}_{\mathrm{DS}}=1.2 \mathrm{~V}$ for CP-BML FET and JL-BML FET. It reveals high $\mathrm{g}_{\mathrm{m}}$ of $1.4 \mathrm{mS} / \mu \mathrm{m}$ and $0.65 \mathrm{mS} / \mu \mathrm{m}$ for CP-BML FET and JL-BML FET observed at 0.825 $\mathrm{V}$ and $1.05 \mathrm{~V}$ respectively. $\mathrm{g}_{\mathrm{m}}$ is a metric to estimate the ability of a device to convert gate voltage to drain current. A low value of $g_{m}$ indicates mobility degradation which generally follows high electric filed and high $\mathrm{g}_{\mathrm{m}}$ is indicative of efficient switching times. Maximum output conductance $\left(\mathrm{g}_{\mathrm{d}, \max }\right)$ of $0.25 \mathrm{mS} / \mu \mathrm{m}$ is observed for CP-BML FET while as $0.12 \mathrm{mS} / \mu \mathrm{m}$ is observed for JL-BML FET at $\mathrm{L}_{\mathrm{G}}=20 \mathrm{~nm}$.
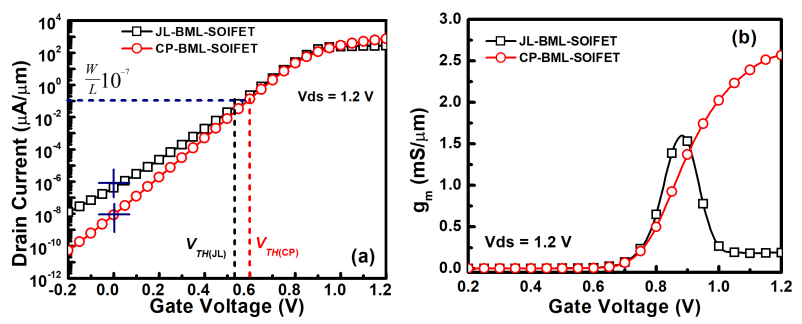

Fig. 3 (a) Transfer characteristics for JL-BML FET and CP-BML FET indicating $\mathrm{V}_{\mathrm{Th}}$ and $\mathrm{I}_{\mathrm{OFF}}$ at $\mathrm{L}_{\mathrm{g}}=20 \mathrm{~nm}$. (b) Transconductance characteristics for JL-BML FET and CPBML FET at $\mathrm{L}_{\mathrm{g}}=20 \mathrm{~nm}$.

Figure 4(a-d) depict the the electron concentration in the silicon device layer of $t_{\mathrm{Si}}=10 \mathrm{~nm}$ for JL-BML FET and CP-BML FET in ON and OFF state. The formation of conducting path (high electron concentration layer) between source and drain regions when the devices are turned from OFF state to ON-state can be observed. For JL-BML FET, in OFF-state the high concentration regions are rendered under source and drain electrodes, the channel area under the influence of high $\phi_{\mathrm{G}}$ of gate is depleted of free charge carriers. On the onset of $\mathrm{V}_{\mathrm{GS}}$, the conducting channel is formed as the flat-band voltage is achieved. In CP-BML FET, the device layer has $\mathrm{N}_{\mathrm{D}}$ of $10^{15} \mathrm{~cm}^{-3}$, where the high concentration source and drain regions are formed by 
charge plasma engineering. The role of BML at the bottom side of device layer creates a schottky junction (depletion region), rendering the charge carrier to surface of the channel in both devices. Since workfunction of silicon $\left(\phi_{\mathrm{Si}}\right)$ is dependent on doping $\mathrm{N}_{\mathrm{D}}$, device with high $\mathrm{N}_{\mathrm{D}}=10^{19} \mathrm{~cm}^{-3}$ (JL-BML FET) has small depletion layer width than device with low $\mathrm{N}_{\mathrm{D}}=$ $10^{15} \mathrm{~cm}^{-3}$ (CP-BML FET). The twofold advantages of introducing a schottky BML include more channel controllability which significantly improves SS and channel thickness variability yielding small DIBL. The schottky barrier height at BML-Si junction significantly affects DIBL of the device as it controls the potential and charge distribution in the channel region. For BML with same $\phi_{\mathrm{BML}}$ in CP-BML FET and JL-BML FET, larger depletion region is formed in CP-BML FET minimizing $\mathrm{I}_{\mathrm{OFF}}$ and DIBL equal to $0.2 \mathrm{pA} / \mu \mathrm{A}$ and $20 \mathrm{mV} / \mathrm{V}$ respectively.

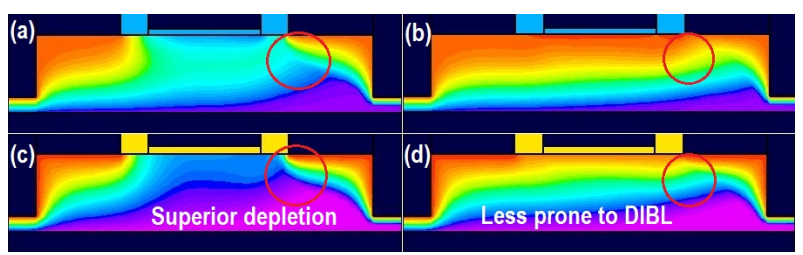

Fig. 4 Contour diagrams showing electron concentration for (a) JL-BML FET in OFF state, (b) JL-BML FET in ON state, (c) CP-BML FET in OFF state, (d) CP-BML FET in ON state.

\subsection{RF Performance Analysis}

Intrinsic capacitances that include gate to source capacitance $\left(\mathrm{C}_{\mathrm{gs}}\right)$ and gate to drain capacitance $\left(\mathrm{C}_{\mathrm{gd}}\right)$ largely affect the frequency performance FOMs of any CMOS devices. Since $\mathrm{C}_{\mathrm{gs}}>\mathrm{C}_{\mathrm{gd}}, \mathrm{C}_{\mathrm{gd}}$ is considered as parasitic or Miller capacitance. It must also be noted that the parasitic capacitance is device geometry dependent that is for multi-gate devices, the parasitic capacitance may be different. The variation of $\mathrm{C}_{\mathrm{gs}}, \mathrm{C}_{\mathrm{gd}}$ w.r.t. $\mathrm{V}_{\mathrm{GS}}$ for JL-BML FET and CP-BML FET is shown in Fig. 5(a-b). In ON-state for $\mathrm{L}_{\mathrm{G}}=20 \mathrm{~nm}, \mathrm{C}_{\mathrm{gs}}$ and $\mathrm{C}_{\mathrm{gd}}$ for JL-BML FET are found to be $0.65 \mathrm{fF} / \mu \mathrm{m}$ and $0.114 \mathrm{fF} / \mu \mathrm{m}$ whereas for CP-BML FET are $0.69 \mathrm{fF} / \mu \mathrm{m}$ and $0.113 \mathrm{fF} / \mu \mathrm{m}$ respectively. One of the important FOM is the transition frequency or cut-off frequency $\left(f_{t}\right)$, depends on $g_{m}$ and $C_{g s}, C_{g d}$. High $g_{m}$ of CP-BML FET yields in higher $f_{t}$ than counterpart technology and has been found to be $460 \mathrm{GHz}$. The frequency characterization FOMs obtained are at par with ITRS performance projections.

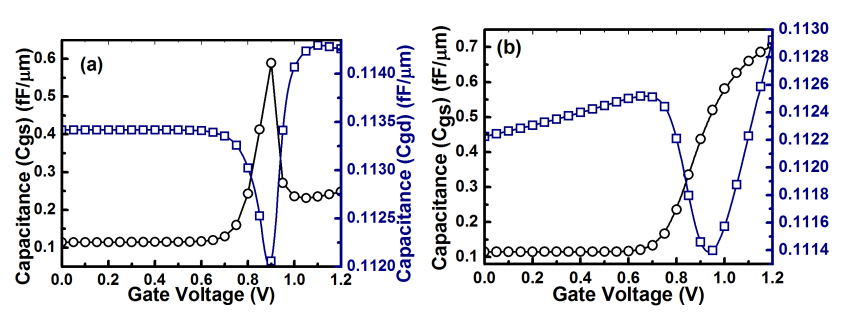

Fig. 5 Capacitance $\left(\mathrm{C}_{g s}, C_{g d}\right)$ in different operating regions for (a) Junctionless BML FET (b) Charge Plasma BML FET.

\subsection{Physical Parameter Dependence of FOMs}

In this section, the dependence of DC and RF performance metrics on criticality of physical parameters that include $\mathrm{L}_{\mathrm{G}}, \phi_{\mathrm{BML}}$, and $\mathrm{t}_{\mathrm{Si}}$ are discussed as follows:
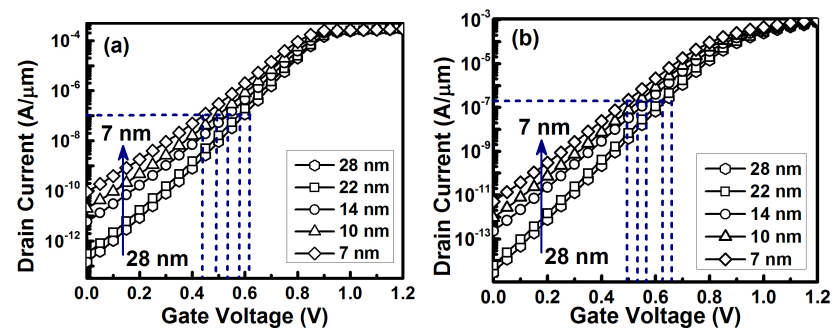

Fig. $6 \mathrm{I}_{\mathrm{D}}$ vs $\mathrm{V}_{\mathrm{GS}}$ at varied $\mathrm{L}_{\mathrm{G}}$ for (a) JL-BML FET (b) CP-BML FET.

\subsubsection{Criticality of Scaling}

$\mathrm{L}_{\mathrm{G}}$ scaling traditionally has resulted in devices with faster speed of operation, low dynamic power at the cost of enhanced SCEs that include increased $\mathrm{I}_{\mathrm{OFF}}$ and DIBL, degradation of SS and $\mathrm{V}_{\mathrm{Th}}$ fluctuations and rolloff. We have analyzed the scalability performance of the proposed device and compared it with performance FOMs of JL-BML FET at ITRS standard technological nodes. Figure $6(\mathrm{a}-\mathrm{b})$ shows transfer characteristics for JL-BML FET and CP-BML FET for $\mathrm{L}_{\mathrm{G}}=28 \mathrm{~nm}$, 22nm, 14nm, 10nm, 7nm. In JL-BML FET, with scaling of $\mathrm{L}_{\mathrm{G}}$ from $28 \mathrm{~nm}$ to $7 \mathrm{~nm}$, I $\mathrm{OFF}$ current increases from $0.144 \mathrm{pA} / \mu \mathrm{m}$ to $92.3 \mathrm{pA} / \mu \mathrm{m}$ yielding an average increase of $4.33 \mathrm{pA} / \mu \mathrm{m} / \mathrm{nm}$, whereas in CP-BML FET, $\mathrm{I}_{\mathrm{OFF}}$ current increases from $2.97 \times 10^{-3} \mathrm{pA} / \mu \mathrm{m}$ to $5.15 \mathrm{pA} / \mu \mathrm{m}$ leading to an average increase of $0.24 \mathrm{pA} / \mu \mathrm{m}$ $/ \mathrm{nm}$. I $\mathrm{OFF}$ mainly breeds from band to band tunneling which in CP-BML FET is minimized by schottky BML which forbids the facilitation of tunneling path to charge carriers in the OFF-state. At $\mathrm{L}_{\mathrm{G}}=7 \mathrm{~nm}$, an acceptable $\frac{\mathrm{I}_{\mathrm{ON}}}{\mathrm{I}_{\mathrm{OFF}}}$ ratio in accordance to ITRS projections of $\simeq 10^{8}$ and $\simeq 10^{6}$ is observed for JL-BML FET and CP-BML FET respectively. 


\subsubsection{Criticality of $\phi_{\mathrm{BML}}$}
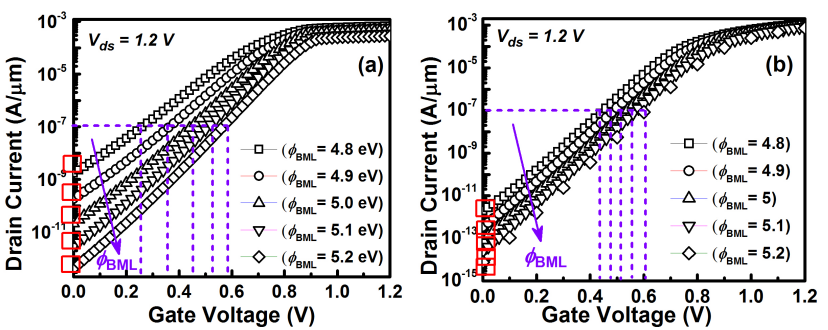

Fig. $7 \mathrm{I}_{\mathrm{D}}-\mathrm{V}_{\mathrm{GS}}$ at varied $\phi_{\mathrm{BML}}$ for (a) JL-BML FET (b) CP-BML FET.

The critical impact of BML workfunction $\left(\phi_{\mathrm{BML}}\right)$ on transfer characteristics of JL-BML FET and CPBML FET is shown in Fig. $7(\mathrm{a}-\mathrm{b})$ for $\mathrm{L}_{\mathrm{G}}=20 \mathrm{~nm}$ and $\mathrm{t}_{\mathrm{Si}}=10 \mathrm{~nm}$. We have analyzed the effect of $\mathrm{I}_{\mathrm{OFF}}$ for $\phi_{\mathrm{BML}}$ varying from $4.8 \mathrm{eV}$ to $5.2 \mathrm{eV}$. With increase in the workfunction of BML, the Schottky barrier height increases, creating superior deletion which renders the channel to surface of the device layer, towards the electrostatic influence of gate. The reduction of effective device layer thickness by creating a no free charge carrier region depending on schottky induced depletion limits the OFF-state current as shown. However considering JL-BML FET, the device layer is inherently highly doped $\left(10^{19} \mathrm{~cm}^{-3}\right)$, the barrier height is compromised as compared to moderately doped device layer in CP-BML-FET. One has to be more careful in choosing $\phi_{\mathrm{BML}}$ with JL-BML FET as the OFF-state needs to be achieved by top gate and not merely by schottky induced depletion. The graphical representation of variance of $\mathrm{I}_{\mathrm{OFF}}, \mathrm{I}_{\mathrm{ON}}$ is shown in Fig. 9(a-c). At $\phi_{\mathrm{BML}}=$ $4.8 \mathrm{eV}$ and $\phi_{\mathrm{BML}}=5.2 \mathrm{eV}$, we have observed $\mathrm{I}_{\mathrm{OFF}}$ of $1.72 \times 10^{-9} \mathrm{~A} / \mu \mathrm{m}$ and $4.29 \times 10^{-13} \mathrm{~A} / \mu \mathrm{m}$ respectively in JL-BML FET yielding an average decrease of $1.71 \mathrm{nA} / \mu / \mathrm{eVm}$ while in CP-BML FET $\mathrm{I}_{\mathrm{OFF}}$ of $2 \times$ $10^{-12} \mathrm{~A} / \mu \mathrm{m}$ at $4.8 \mathrm{eV}$ and $7.69 \times 10^{-15} \mathrm{~A} / \mu \mathrm{m}$ at 5.2 $\mathrm{eV}$ is observed yielding an average decrease in $\mathrm{I}_{\mathrm{OFF}}$ of $1.99 \mathrm{pA} / \mu \mathrm{m} / \mathrm{eV}$.

\subsubsection{Criticality of $\mathrm{t}_{\mathrm{Si}}$}

The device layer thickness $\left(t_{\mathrm{Si}}\right)$ is a physical parameter of critical for determination of device characteristics in such kind of architectures. The volume of charge carriers depends on $t_{\mathrm{Si}}$ which will ultimately determine the FOMs like $\mathrm{I}_{\mathrm{OFF}}, \mathrm{V}_{\mathrm{Th}}$, and SS. Figure $8(\mathrm{a}-\mathrm{b})$ shows device characteristics for varied $t_{\mathrm{Si}}$ for JL-BML FET and CP-BML FET. In JL-BML FET, increasing $t_{\mathrm{Si}}$ beyond $10 \mathrm{~nm}$ leads to increase in $\mathrm{I}_{\mathrm{OFF}}$ due to inability of high
Table 2 Workfunction of schottky BML for different extent of depletion depths $\left(\mathrm{y}_{\mathrm{dep}}, \mathrm{BML}\right)$ for different device layer thickness $\left(t_{\mathrm{Si}}\right)$ and channel doping concentrations $\left(\mathrm{N}_{\mathrm{D}}\right)$.

\begin{tabular}{|c|c|c|}
\hline $\mathrm{N}_{\mathrm{D}}, \mathrm{t}_{\mathrm{Si}}$ & $\mathrm{y}_{\text {dep, }}$ BML $\%$ age & $\phi_{\mathrm{BML}}$ \\
\hline $\mathrm{N}_{\mathrm{D}}=10^{19} \mathrm{~cm}^{-3}, \mathrm{t}_{\mathrm{Si}}=10 \mathrm{~nm}$ & $100 \%(10 \mathrm{~nm})$ & $5.88 \mathrm{eV}$ \\
\hline $\mathrm{N}_{\mathrm{D}}=10^{19} \mathrm{~cm}^{-3}, t_{S i}=10 \mathrm{~nm}$ & $50 \%(5 \mathrm{~nm})$ & $5.31 \mathrm{eV}$ \\
\hline $\mathrm{N}_{\mathrm{D}}=10^{19} \mathrm{~cm}^{-3}, \mathrm{t}_{\mathrm{Si}}=10 \mathrm{~nm}$ & $20 \%(2 \mathrm{~nm})$ & $5.12 \mathrm{eV}$ \\
\hline $\mathrm{N}_{\mathrm{D}}=10^{19} \mathrm{~cm}^{-3}, \mathrm{t}_{\mathrm{Si}}=50 \mathrm{~nm}$ & $100 \%(50 \mathrm{~nm})$ & $\mathrm{NE}$ \\
\hline $\mathrm{N}_{\mathrm{D}}=10^{19} \mathrm{~cm}^{-3}, \mathrm{t}_{\mathrm{Si}}=50 \mathrm{~nm}$ & $50 \%(25 \mathrm{~nm})$ & $9.9 \mathrm{eV}$ \\
\hline $\mathrm{N}_{\mathrm{D}}=10^{19} \mathrm{~cm}^{-3}, \mathrm{t}_{\mathrm{Si}}=50 \mathrm{~nm}$ & $20 \%(10 \mathrm{~nm})$ & $5.88 \mathrm{eV}$ \\
\hline $\mathrm{N}_{\mathrm{D}}=10^{16} \mathrm{~cm}^{-3}, \mathrm{t}_{\mathrm{Si}}=10 \mathrm{~nm}$ & $100 \%(10 \mathrm{~nm})$ & $4.95 \mathrm{eV}$ \\
\hline $\mathrm{N}_{\mathrm{D}}=10^{16} \mathrm{~cm}^{-3}, \mathrm{t}_{\mathrm{Si}}=10 \mathrm{~nm}$ & $50 \%(5 \mathrm{~nm})$ & $4.95 \mathrm{eV}$ \\
\hline $\mathrm{N}_{\mathrm{D}}=10^{16} \mathrm{~cm}^{-3}, \mathrm{t}_{\mathrm{Si}}=10 \mathrm{~nm}$ & $20 \%(2 \mathrm{~nm})$ & $4.9 \mathrm{eV}$ \\
\hline $\mathrm{N}_{\mathrm{D}}=10^{16} \mathrm{~cm}^{-3}, \mathrm{t}_{\mathrm{Si}}=50 \mathrm{~nm}$ & $100 \%(50 \mathrm{~nm})$ & $4.97 \mathrm{eV}$ \\
\hline $\mathrm{N}_{\mathrm{D}}=10^{16} \mathrm{~cm}^{-3}, \mathrm{t}_{\mathrm{Si}}=50 \mathrm{~nm}$ & $50 \%(25 \mathrm{~nm})$ & $4.96 \mathrm{eV}$ \\
\hline $\mathrm{N}_{\mathrm{D}}=10^{16} \mathrm{~cm}^{-3}, \mathrm{t}_{\mathrm{Si}}=50 \mathrm{~nm}$ & $20 \%(10 \mathrm{~nm})$ & $4.95 \mathrm{eV}$ \\
\hline where, $\phi_{\mathrm{BML}}=\phi_{\mathrm{Si}}+\frac{\mathrm{N}_{\mathrm{D}^{\mathrm{t}}}^{2}}{2 \epsilon_{\mathrm{Si}}}$ & $\frac{T+V_{B M L}}{q}$ & \\
\hline
\end{tabular}

workfunction gate to deplete the highly doped channel efficiently. However in CP-BML FET, the channel is moderately intrinsic therefore $\mathrm{I}_{\mathrm{OFF}}$ is somewhat controlled. It must be noted that selection of $\phi_{\mathrm{BML}}$ and $\mathrm{t}_{\mathrm{Si}}$ are interdependent and have to be chosen carefully. The dependence of $\phi_{\mathrm{BML}}$ for different depletion depths in JL-BML FET and CP-BML FET with varied $t_{\mathrm{Si}}$ is calculated analytically listed in Table 2 . It is analyzed that $\mathrm{I}_{\mathrm{OFF}}$ is significantly affected by $\mathrm{t}_{\mathrm{Si}}$ and $\mathrm{N}_{\mathrm{D}}$ as shown in Fig. 9(c). Since the effective $t_{\mathrm{Si}}$ in CP-BML FET depends on $\lambda_{\mathrm{D}}$, such doping less architectures FETs are immune to variations in physical parameters as compared to chemically doped devices.
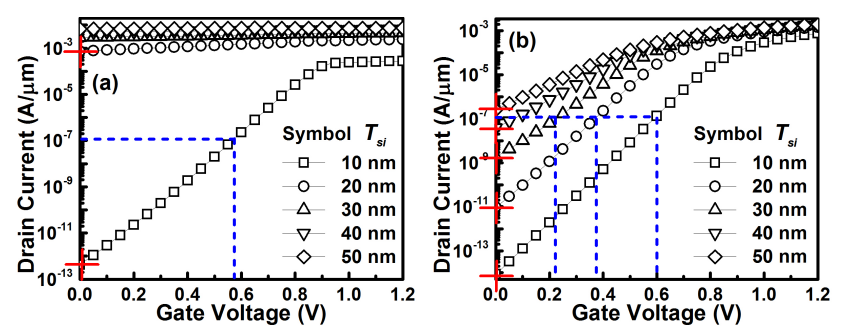

Fig. $8 I_{D}$ vs $V_{G S}$ at varied $t_{S i}$ for (a) JL-BML FET (b) CP-BML FET.

\subsection{Performance along ITRS Scaling Roadmap Considerations}

In this section, different FOMs for JL-BML FET and CP-BML FET are compared for scaling of $\mathrm{L}_{\mathrm{G}}$. A tabular list of all the considered FOMs for different $\mathrm{L}_{\mathrm{G}}$ are listed in Table 3. At $\mathrm{L}_{\mathrm{G}}=7 \mathrm{~nm}, \mathrm{I}_{\text {sat }}$ value of $293 \mu \mathrm{A} / \mu \mathrm{m}$ and $975 \mu \mathrm{A} / \mu \mathrm{m}$ is observed for JL-BML FET and CPBML FET respectively which is at par with ITRS 2025 low power requirements. For ultra scaled devices $\left(\mathrm{L}_{\mathrm{G}}=7 \mathrm{~nm}\right)$, the JL-BML FET shows $\mathrm{V}_{\mathrm{Th}}$ roll-off of $100 \mathrm{mV}$ while as 

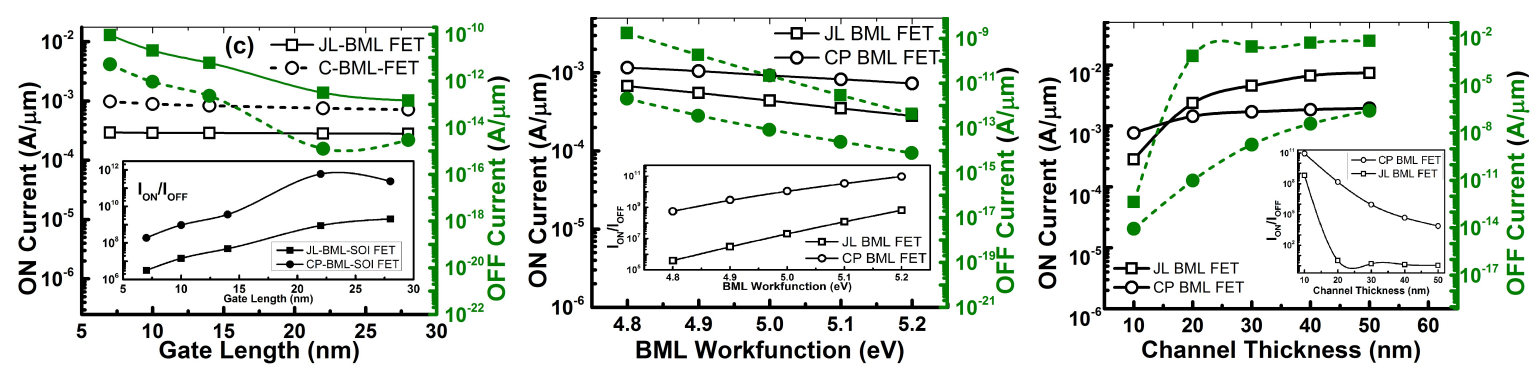

Fig. $9 \mathrm{I}_{\mathrm{ON}}, \mathrm{I}_{\mathrm{OFF}}$ variations for different (a) $\mathrm{L}_{\mathrm{G}}$ (b) BML workfunction (c) $\mathrm{t}_{\mathrm{Si}}$. Insets shows corresponding $\mathrm{I}_{\mathrm{ON}} / \mathrm{I}_{\mathrm{OFF}}$ variations.

Table 3 Performance FOMs for JL-BML FET and CP-BML FET for $\mathrm{L}_{\mathrm{g}}$ scaling.

\begin{tabular}{|c|c|c|c|c|c|c|c|c|c|c|}
\hline \multirow[t]{2}{*}{ Parameter } & \multicolumn{5}{|c|}{$\begin{array}{l}\text { Junctionless Buried Metal Layer FET } \\
\text { Technology Node: Gate Length (nm) }\end{array}$} & \multicolumn{5}{|c|}{$\begin{array}{l}\text { Charge Plasma Buried Metal Layer FET } \\
\text { Technology Node: Gate Length (nm) }\end{array}$} \\
\hline & 7 & 10 & 14 & 22 & 28 & 7 & 10 & 14 & 22 & 28 \\
\hline $\mathrm{I}_{\mathrm{On}}(\mu \mathrm{A} / \mu \mathrm{m})$ & 293 & 289 & 287 & 281 & 270 & 975 & 889 & 832 & $\begin{array}{l}750 \\
\end{array}$ & 712 \\
\hline $\mathrm{I}_{\mathrm{Off}}(\mathrm{pA} / \mu \mathrm{m})$ & 92.3 & 20.2 & 5.94 & .313 & .144 & 5.15 & .924 & .228 & $6.26 \times 10^{-2}$ & $2.97 \times 10^{-3}$ \\
\hline $\mathrm{I}_{\text {On }} / \mathrm{I}_{\text {Off }}\left(\times 10^{6}\right)$ & 3 & 14 & 48 & 890 & $1.87 \times 10^{3}$ & 189 & 960 & $3.6 \times 10^{3}$ & $1.19 \times 10^{5}$ & $2.4 \times 10^{5}$ \\
\hline $\mathrm{V}_{\mathrm{Th}}$ Roll - off $(\mathrm{mV})$ & 100 & 65 & 40 & 22 & 18 & 80 & 55 & 35 & 20 & 15 \\
\hline $\mathrm{SS}(\mathrm{mV} / \mathrm{dec})$ & 118 & 115 & 110 & 90 & 80 & 108 & 100 & 80 & 75 & 65 \\
\hline $\mathrm{g}_{\mathrm{m}}(\mathrm{mS} / \mu \mathrm{m})$ & 1.59 & 1.74 & 1.65 & 1.54 & 1.52 & 2.7 & 2.66 & 2.63 & 2.56 & 2.53 \\
\hline $\mathrm{C}_{\mathrm{gs}}(\mathrm{fF} / \mu \mathrm{m})$ & 0.31 & 0.40 & 0.52 & 0.72 & 0.86 & 0.38 & 0.46 & 0.56 & 0.75 & 0.90 \\
\hline $\mathrm{C}_{\mathrm{gd}}(\mathrm{fF} / \mu \mathrm{m})$ & 0.1137 & 0.1162 & 0.118 & 0.121 & 0.124 & 0.109 & 0.111 & 0.113 & 0.113 & 0.114 \\
\hline $\mathrm{f}_{\mathrm{T}}(\mathrm{GHz})$ & 560 & 528 & 407 & 290 & 244 & 866 & 739 & 622 & 468 & 396 \\
\hline $\mathrm{GBP}(\mathrm{GHz})$ & 222 & 238 & 222 & 202 & 195 & 394 & 381 & 370 & 360 & 353 \\
\hline $\operatorname{TGF}\left(\mathrm{V}^{-1}\right)$ & 5.42 & 6.02 & 5.74 & 5.48 & 5.62 & 2.76 & 2.99 & 3.16 & 3.41 & 3.55 \\
\hline $\mathrm{TFP}(\mathrm{THz})$ & 3.035 & 3.178 & 2.336 & 1.589 & 1.371 & 2.390 & 2.209 & 1.965 & 1.595 & 1.405 \\
\hline$\tau($ psec $)$ & 1.75 & 2.17 & 2.69 & 3.62 & 4.4 & 0.6 & 0.77 & 0.97 & 1.3 & 1.71 \\
\hline $\mathrm{P}_{\mathrm{dyn}}(\mathrm{fJ} / \mu \mathrm{m})$ & 0.309 & 0.620 & 0.86 & 1.36 & 1.72 & 0.248 & 0.496 & 0.695 & 1.09 & 1.39 \\
\hline
\end{tabular}

Table 4 Comparative analysis of technologies for various FOMs

\begin{tabular}{|c|c|c|c|c|c|c|c|c|}
\hline Device Description & Tech. $\left(\mathrm{L}_{\mathrm{g}}\right)$ & $\mathrm{I}_{\mathrm{ON}}$ & $\mathrm{I}_{\mathrm{OFF}}(\mu \mathrm{A} / \mu \mathrm{m})$ & $\frac{\mathrm{I}_{\mathrm{ON}}}{\mathrm{I}_{\mathrm{OFF}}}$ & $\mathrm{SS}(\mathrm{mV} / \mathrm{dec})$ & $\tau$ & $\mathrm{P}_{\mathrm{dyn}}(\mathrm{fJ} / \mu \mathrm{m})$ & [Ref] \\
\hline Charge Plasma SOI FET with BML & $20 \mathrm{~nm}$ & $730 \mu \mathrm{A} / \mu \mathrm{m})$ & $7.69 \times 10^{-9}$ & $10^{11}$ & 75 & $1.3 \mathrm{ps}$ & 1.09 & [This Work] \\
\hline Junctionless SOI FET with BML & $20 \mathrm{~nm}$ & $261 \mu \mathrm{A} / \mu \mathrm{m})$ & $1.3 \times 10^{-6}$ & $10^{8}$ & 90 & $3.62 \mathrm{ps}$ & 1.36 & [This Work], [20] \\
\hline Planar Junctionless SOI FET & $1 \mu \mathrm{m}$ & $100 \mu \mathrm{A} / \mu \mathrm{m}$ & 50 & $10^{2}$ & 150 & - & - & {$[17]$} \\
\hline Tunnel Field Effect Transistor & $13 \mathrm{~nm}$ & $10 \mu \mathrm{A} / \mu \mathrm{m})$ & $1 \mathrm{nA} / \mu \mathrm{m}$ & $10^{5}$ & 60 & $20 \mathrm{ps}$ & ULP & [21] \\
\hline Negative Capacitance FET & $80 \mathrm{~nm}$ & $1 \mathrm{~mA} / \mu$ & $10^{-5}$ & $10^{8}$ & 53.3 & $10 \mathrm{ps}$ & - & [22] \\
\hline MOS Planar HEMT & $50 \mathrm{~nm}$ & $2.7 \mathrm{~A} / \mathrm{mm}$ & Normally-On & - & - & $0.2 \mathrm{~ns}$ & High Power & [23] \\
\hline Planar Schottky Barrier MOSFET & $40 \mathrm{~nm}$ & $0.17 \mu \mathrm{A} / \mu \mathrm{m})$ & $2.1 \times 10^{-3}$ & $10^{4}$ & 147.87 & $0.1 \mathrm{~ns}$ & - & [24] \\
\hline
\end{tabular}

80mV CP-BML FET is observed in CP-BML FET. $\mathrm{V}_{\text {Th }}$ roll-off reduces for higher technology nodes indicating the dominance of SCEs for ultra-scaled devices. The SS drops below the thermal limit of $60 \mathrm{mV} / \mathrm{dec}$ with progressive scaling of $\mathrm{L}_{\mathrm{G}}$ but is observed to be more severe in JL-BML FET than the proposed device. The transition or cut-off frequency is given by $\mathrm{f}_{\mathrm{t}}=\frac{\mathrm{g}_{\mathrm{m}}}{2 \pi\left(\mathrm{C}_{\mathrm{gs}}+\mathrm{C}_{\mathrm{gd}}\right)}$. Due to high $\mathrm{g}_{\mathrm{m}}$ and lower $\mathrm{C}_{\mathrm{gs}}, \mathrm{C}_{\mathrm{gd}}$ in CP-BML FET, $\mathrm{f}_{\mathrm{t}}$ of $806 \mathrm{GHz}$ is observed while as $\mathrm{f}_{\mathrm{t}}$ of $560 \mathrm{GHz}$ is observed in JL-BML FET. Current gain and unilateral power gain were obtained using s-parameter analysis shown in Fig. 10(a) and (b). The cut-off frequencies were obtained using slope of $-20 \mathrm{~dB} /$ decade.

Gain bandwidth product (GBP) represents the region of operation of FET for which the gain remains constant calculated for DC gain of 10 using $\frac{g_{m}}{20 \pi \mathrm{C}_{g d}}$ [25]. Stable high frequency performance is observed in CPBML FET as compared to JL-BML FET for which the GBP improves with scaling and at $\mathrm{L}_{\mathrm{g}}=7 \mathrm{~nm}$ is found
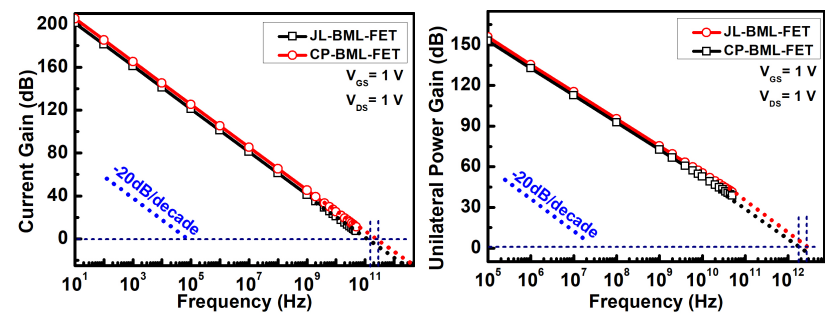

Fig. 10 (a) Current gain vs frequency (b) Power gain vs frequency.

to be $394 \mathrm{GHz}$ for CP-BML FET. One of the important modern day FOMs for applications like fast mixed signal design include transconductance generation factor $\left(\mathrm{TGF}=\mathrm{g}_{\mathrm{m}} / \mathrm{I}_{\mathrm{ds}}\right)$ and transconductance frequency product $\left(\mathrm{TFP}=\mathrm{TGF} \times \mathrm{f}_{\mathrm{t}}\right)$. Both FOMs are computed and have been listed in Table 3 for scaled $\mathrm{L}_{\mathrm{g}}$. Two of the major generic FOMs include the intrinsic delay $(\tau)$ and dynamic power consumption $\left(\mathrm{P}_{\text {dyn }}\right) . \tau$ has been computed using $\mathrm{C}_{\mathrm{gg}} \mathrm{V}_{\mathrm{DS}} / \mathrm{I}_{\mathrm{sat}}$. It is found that for $\mathrm{ul}$ 


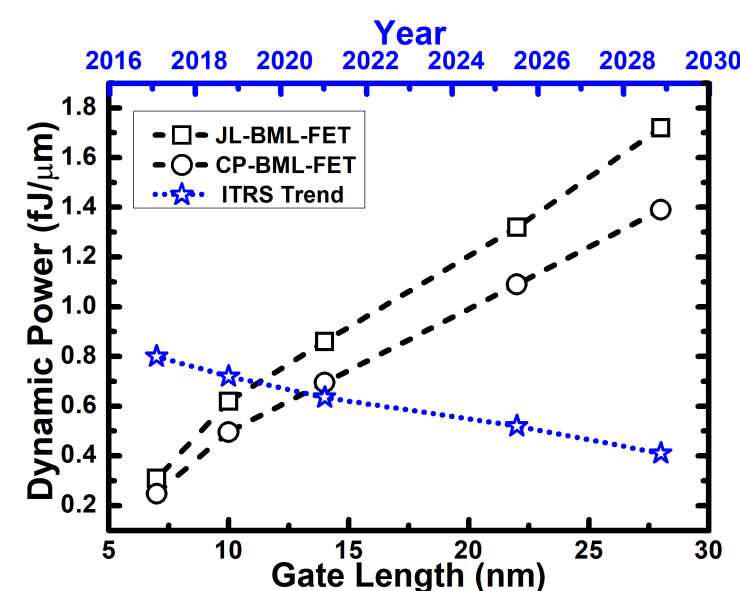

Fig. 11 Dynamic power requirement for different $L_{G}$ with ITRS trend.

tra scaled CP-BML FET exhibits $\tau$ of 0.6 psec which is superior to ITRS projections. $\tau$ of 1.71 psec at 28 $\mathrm{nm}$ technology node is quiet a desired feature as per 2028 ITRS projections. $\mathrm{P}_{\text {dyn }}$ per $\mathrm{W}$ is computed using $\mathrm{C}_{\mathrm{ox}}\left(\mathrm{V}_{\mathrm{DS}}\right)^{2} \mathrm{fJ} / \mu \mathrm{m}$. ITRS projects that in $2028, \mathrm{P}_{\mathrm{dyn}}$ is scaled down to $0.32 \mathrm{fJ} / \mu \mathrm{m}$ at $\mathrm{L}_{\mathrm{g}}=7 \mathrm{~nm}$. The proposed CP-BML FET yields $\mathrm{P}_{\text {dyn }}$ of $0.248 \mathrm{fJ} / \mu \mathrm{m}$ at $\mathrm{L}_{\mathrm{g}}=7 \mathrm{~nm}$ with elevated $\mathrm{V}_{\mathrm{DD}}$ as shown in Fig. 11. The obtained valued of $\mathrm{P}_{\mathrm{dyn}}$ and $\tau$ implicate high performance and ultra low power operation of the proposed device.

\section{Performance comparison with counterpart technologies}

Maintaining performance consistency amid downscaling of devices is an unrealistic thing to achieve. In this section we compare some generic technologies with the proposed work shown in Table 4. Tunneling FET is one of the classical approaches to surpass the thermal limit $(60 \mathrm{mV} / \mathrm{dec})$ of $\mathrm{SS}$ at downscaled dimensions of $\mathrm{L}_{\mathrm{g}}$. TFET with $\mathrm{L}_{\mathrm{g}}=13 \mathrm{~nm}$, has $\mathrm{SS}$ of $60 \mathrm{mV} /$ dec with improved $\mathrm{I}_{\mathrm{ON}} / \mathrm{I}_{\mathrm{OFF}}$ ratio with excellent power performance suitable for digital applications however the limited $\mathrm{I}_{\mathrm{ON}}$ renders the fan-out of the circuit [26]. This problem is the foreground for its wide application particularly at smaller technology nodes. In the recent past, new class of devices with non-classical design approach with steep subthreshold slope device have been proposed called negative capacitance FETs. A device of $\mathrm{L}_{\mathrm{g}}=80 \mathrm{~nm}$, has a good ON current, better $\mathrm{I}_{\mathrm{ON}} / \mathrm{I}_{\mathrm{OFF}}$ ratio with excellent $\mathrm{SS}$ of $53.3 \mathrm{mV} / \mathrm{dec}$ but suffers from fabrication complexities which involves integration of ferroelectric material in the design [22]. Such FETs have hysteresis effect which increase the intrinsic delay of the device. High electron mobility transistor (HEMT) is cost ineffective normally ON device offering high leakage current and high power consumption limiting its ap- plicability. Apart from proposed work, all device technologies listed in Table 4 involve chemical doping increasing the thermal budget adjoined by scaling limitation to such technologies. The proposed work involves charge plasma charge carrier induction technique without chemical doping. The device in comparison to other technology devices have high performance and low power requirements. The SS OF $75 \mathrm{mV} / \mathrm{dec}$ at $\mathrm{L}_{\mathrm{g}}=20 \mathrm{~nm}$ with $\mathrm{I}_{\mathrm{ON}} / \mathrm{I}_{\mathrm{OFF}}=10^{11}$ ratio make it competitive candidate for low power requirements particularly at lower technology nodes in accordance to ITRS performance projections. The obtained FMOs indicate at par performance of proposed than complex structured devices enabled with state of the art technologies.

\section{Conclusions}

Through this work deliver a novel architecture scheme of planar FET design that is significantly advantageous from design, fabrication and performance perspectives. The proposed FET is doping-free transistor with a schottky buried metal layer to induce depletion layer reducing the effective thickness of the device layer. The inclusion of BML in conjunction with charge plasma mechanism reveals a prospective strategy for suppression of SCEs in planar single gate FETs. The proposed FET has been investigated for DC and RF performance FOMs with emphasis on ITRS projections of scaling from $28 \mathrm{~nm}$ to $7 \mathrm{~nm}$. The criticality of physical parameter dependence including $\mathrm{L}_{\mathrm{g}}, \mathrm{T}_{\mathrm{Si}}, \phi_{\mathrm{BML}}$ on performance has been investigated in detail. For $\mathrm{L}_{\mathrm{g}}=$ $20 \mathrm{~nm}$, and $\mathrm{V}_{\mathrm{DS}}=1.2 \mathrm{~V}$, the proposed device has superior $\frac{\mathrm{I}_{\mathrm{ON}}}{\mathrm{I}_{\mathrm{OFF}}}$ ratio of $10^{11}$ and $\mathrm{SS}$ of $75 \mathrm{mV} / \mathrm{dec}$, also $\mathrm{I}_{\mathrm{ON}}$ and $\mathrm{I}_{\mathrm{OFF}}$ for CP-BML FET read at $730 \mu \mathrm{A} / \mu \mathrm{m}$ and $7 \times 10^{-2} \mathrm{pA} / \mu \mathrm{m}$ respectively at par with ITRS 2025 performance requirement. With equivalent scaling of $\mathrm{L}_{\mathrm{g}}$ from $28 \mathrm{~nm}$ to $7 \mathrm{~nm}, \mathrm{I}_{\mathrm{OFF}}$ meagerly increased at rate of $0.24 \mathrm{pA} / \mu \mathrm{m} / \mathrm{nm}$ yielding promising results for sub $10 \mathrm{~nm}$ technology node. At $\mathrm{L}_{\mathrm{G}}=7 \mathrm{~nm}, \mathrm{I}_{\text {sat }}$ value of $293 \mu \mathrm{A} / \mu \mathrm{m}$ and $975 \mu \mathrm{A} / \mu \mathrm{m}$ is observed for JL-BML FET and CP-BML FET respectively satisfying ITRS 2025 low power requirements. The power consumption and intrinsic delay performance for $28 \mathrm{~nm}$ to $7 \mathrm{~nm}$ technology nodes are in resonance with ITRS requirements and a desirable diminished trade-off between power and delay is observed in the proposed device. The obtained FOMs of the proposed device make it a potential candidate for low power operations especially with planar single gate architecture FETs. 


\section{Acknowledgments}

The authors would like to thank head of the department, Department of Electronics and Communication Engineering, Malaviya National Institute of Technology for providing necessary support for carrying out the simulation work.

\section{Author's Contributions}

The main conception of this work is brainchild of $\mathrm{N}$. Shafi (Author 1). A. M. Bhat, J. S. Parmar and A. Powral provided the necessary support regarding simulation and data interpretation. C. Sahu and C. Periasamy supervised the work and made important discussions and modifications to the final manuscript.

\section{Funding}

The authors have not received any funding for this work.

\section{Data Availability}

There are no linked research data sets for this submission.

\section{Conflict of interest}

The authors declare that they have no conflict of interest.

\section{Ethical Approval}

All procedures performed in studies involving human participants were in accordance with the ethical standards of the institutional and/or national research committee and with the 1964 Helsinki declaration and its later amendments or comparable ethical standards.

\section{Informed Consent}

Informed consent was obtained from all individual participants included in the study.

\section{References}

1. B. Sheu, K. Olstein, IEEE Solid-State Circuits Magazine 7(2), 67 (2015). URL 10.1109/MSSC.2015.2418472

2. F. Ávila Herrera, Y. Hirano, M. Miura-Mattausch, T. Iizuka, H. Kikuchihara, H.J. Mattausch, A. Ito, IEEE Transactions on Electron Devices 66(9), 3726 (2019). URL 10.1109/TED.2019.2931749

3. N. Jaiswal, A. Kranti, IEEE Transactions on Electron Devices 65(9), 3669 (2018). $\quad$ URL 10.1109/TED.2018.2856839

4. G.V. Angelov, D.N. Nikolov, M.H. Hristov, Journal of Electrical and Computer Engineering 2019, 4792461 (2019). DOI 10.1155/2019/4792461. URL https://doi.org/10.1155/2019/4792461

5. P. Gargini, in 2017 Fifth Berkeley Symposium on Energy Efficient Electronic Systems Steep Transistors Workshop (E3S) (2017), pp. 1-62. URL 10.1109/E3S.2017.8246153

6. Wei-Yuan Lu, Yuan Taur, IEEE Transactions on Electron Devices 53(5), 1137 (2006). URL 10.1109/TED.2006.871879

7. A. Pacheco-Sanchez, D. Loroch, S. Mothes, M. Schröter, M. Claus, in 2016 International Conference on Simulation of Semiconductor Processes and Devices (SISPAD) (2016), pp. 277-280. URL 10.1109/SISPAD.2016.7605201

8. S. Sahay, M.J. Kumar, IEEE Transactions on Electron Devices 64(6), 2604 (2017). URL 10.1109/TED.2017.2688134

9. Q. Xie, Z. Wang, Y. Taur, IEEE Transactions on Electron Devices 64(8), 3511 (2017). URL 10.1109/TED.2017.2716969

10. N. Shafi, C. Sahu, C. Periasamy, IEEE Electron Device Letters 40(6), 997 (2019). URL 10.1109/LED.2019.2911334

11. J.P. Colinge, C.W. Lee, A. Afzalian, N.D. Akhavan, R. Yan, I. Ferain, P. Razavi, B. O'Neill, A. Blake, M. White, A.M. Kelleher, B. McCarthy, R. Murphy, Nature Nanotechnology 5(3), 225 (2010). DOI 10.1038/nnano.2010.15. URL https://doi.org/10.1038/nnano.2010.15

12. J. Colinge, A. Kranti, R. Yan, C. Lee, I. Ferain, R. Yu, N. Dehdashti Akhavan, P. Razavi, SolidState Electronics 65-66, 33 (2011). DOI https://doi.org/10.1016/j.sse.2011.06.004. Selected Papers from the ESSDERC 2010 Conference

13. C. Sahu, J. Singh, IEEE Electron Device Letters 35(3), 411 (2014). URL 10.1109/LED.2013.2297451

14. R.J.E. Hueting, B. Rajasekharan, C. Salm, J. Schmitz, IEEE Electron Device Letters 29(12), 1367 (2008). DOI 10.1109/LED.2008.2006864. URL 10.1109/LED.2008.2006864

15. A. Lahgere, M.J. Kumar, IEEE Transactions on Electron Devices 64(1), 3 (2017). URL 10.1109/TED.2016.2622741

16. Partha Sarathi Gupta, S. Kanungo, H. Rahaman, Partha Sarathi Dasgupta, in 2012 International Conference on Computing, Electronics and Electrical Technologies (ICCEET) (2012), pp. 761-765. URL 10.1109/ICCEET.2012.6203784

17. S. Gundapaneni, S. Ganguly, A. Kottantharayil, IEEE Electron Device Letters 32(3), 261 (2011). URL 10.1109/LED.2010.2099204

18. N. Shafi, C. Sahu, C. Periasamy, IEEE Sensors Journal 20(9), 4749 (2020). URL 10.1109/JSEN.2020.2964625 
19. N. Shafi, C. Sahu, C. Periasamy, Superlattices and Microstructures 120, 75 (2018). URL 10.1016/j.spmi.2018.05.006

20. M. Ehteshamuddin, S.A. Loan, M. Rafat, IEEE Electron Device Letters 39(6), 799 (2018). URL 10.1109/LED.2018.2829915

21. U.E. Avci, D.H. Morris, I.A. Young, IEEE Journal of the Electron Devices Society 3(3), 88 (2015). URL 10.1109/JEDS.2015.2390591

22. K. Lee, J. Lee, S. Kim, R. Lee, S. Kim, M. Kim, J. Lee, S. Kim, B. Park, IEEE Transactions on Nanotechnology 19, 168 (2020). URL 10.1109/TNANO.2020.2972605

23. W. Chen, J. Zhang, Q. He, H. Zhou, X. Huang, Z. Ren, K. Su, W. Mao, J. Xue, X. Zheng, J. Zhang, Y. Hao, IEEE Transactions on Electron Devices 66(11), 4673 (2019). URL 10.1109/TED.2019.2940504

24. S. Kale, P.N. Kondekar, IEEE Transactions on Electron Devices 64(11), 4400 (2017). URL 10.1109/TED.2017.2754881

25. M.R. Tripathy, A.K. Singh, A. Samad, P.K. Singh, K. Baral, S. Jit, Semiconductor Science and Technology 35(10), 105014 (2020). URL 10.1088/1361-6641/aba418

26. E. Yu, W.J. Lee, J. Jung, S. Cho, IEEE Transactions on Electron Devices PP, 1 (2018). URL 10.1109/TED.2018.2808764 
Figures
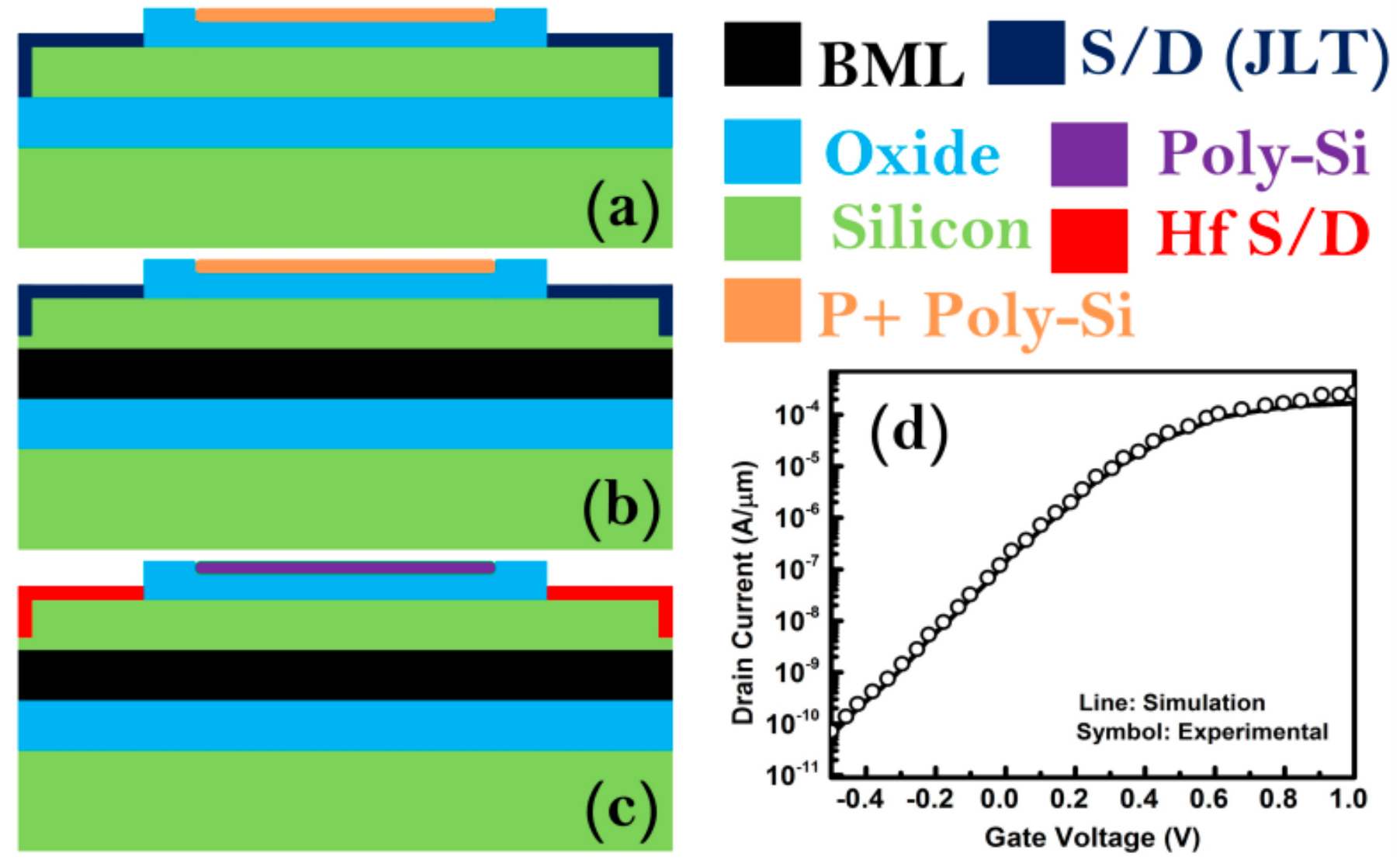

Figure 1

(a) Conventional bulk planar junctionless SOI FET [17], (b) Bulk planar junctionless with buried metal layer FET, (c) Proposed charge plasma induced dopingless source drain fully depleted buried metal layer planar FET (d) Ex冈perimental calibration of simulation model for BP-JLT with [17]. 

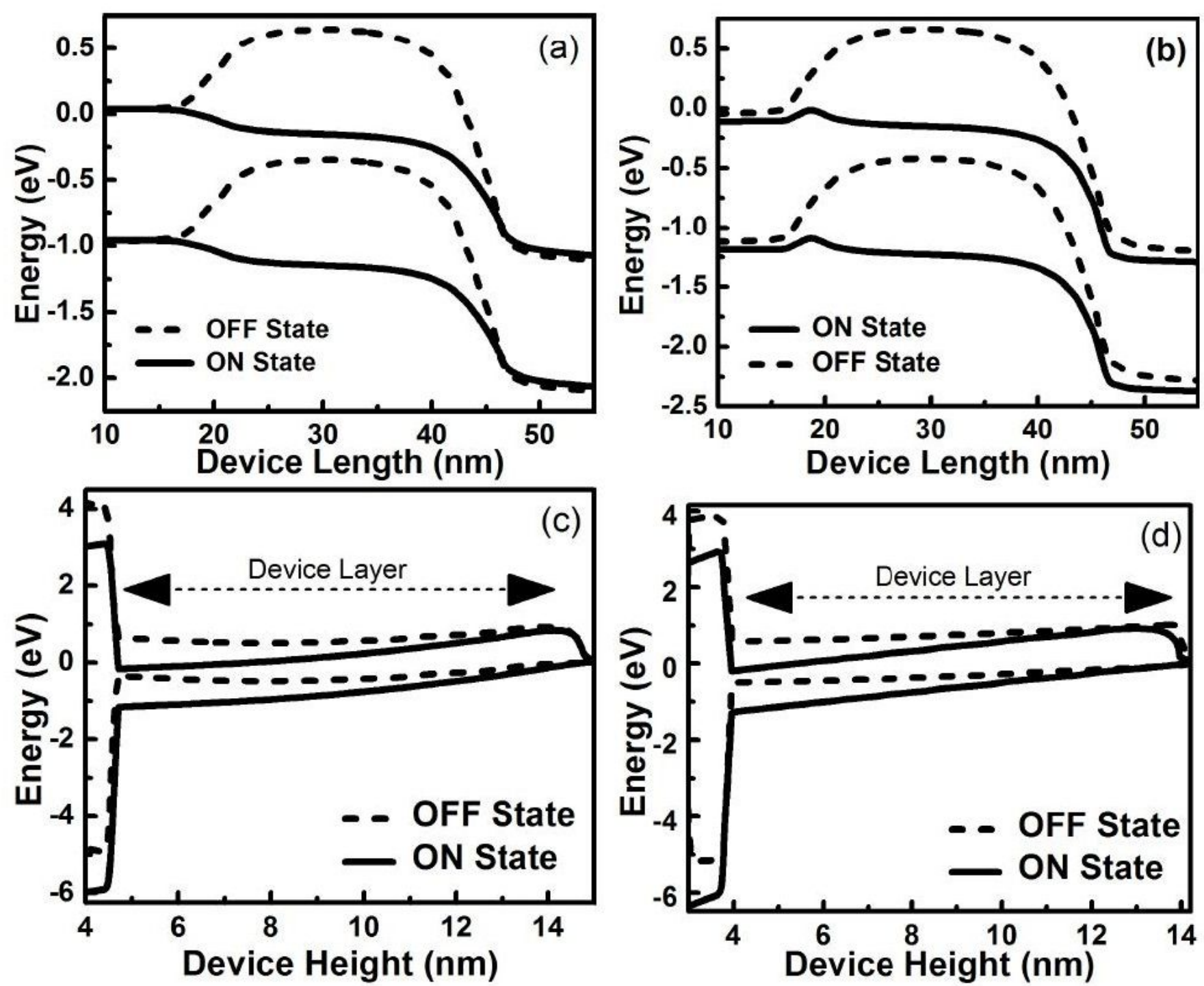

Figure 2

(a). Horizontal energy band variation for JL-BML囚SOI FET in OFF and ON state, (b). Horizontal energy band variation for CP-BML-SOI FET in OFF and ON state, (c). Vertical energy band variation in channel for JL-BML-SOI FET in OFF and ON state, (d). Vertical energy band vari囚ation in channel for CP-BML-SOI FET in OFF and ON state. OFF state @ Vgs=0V, Vds=1.2V, ON state @ Vgs=1.2V, Vds=1.2V. 

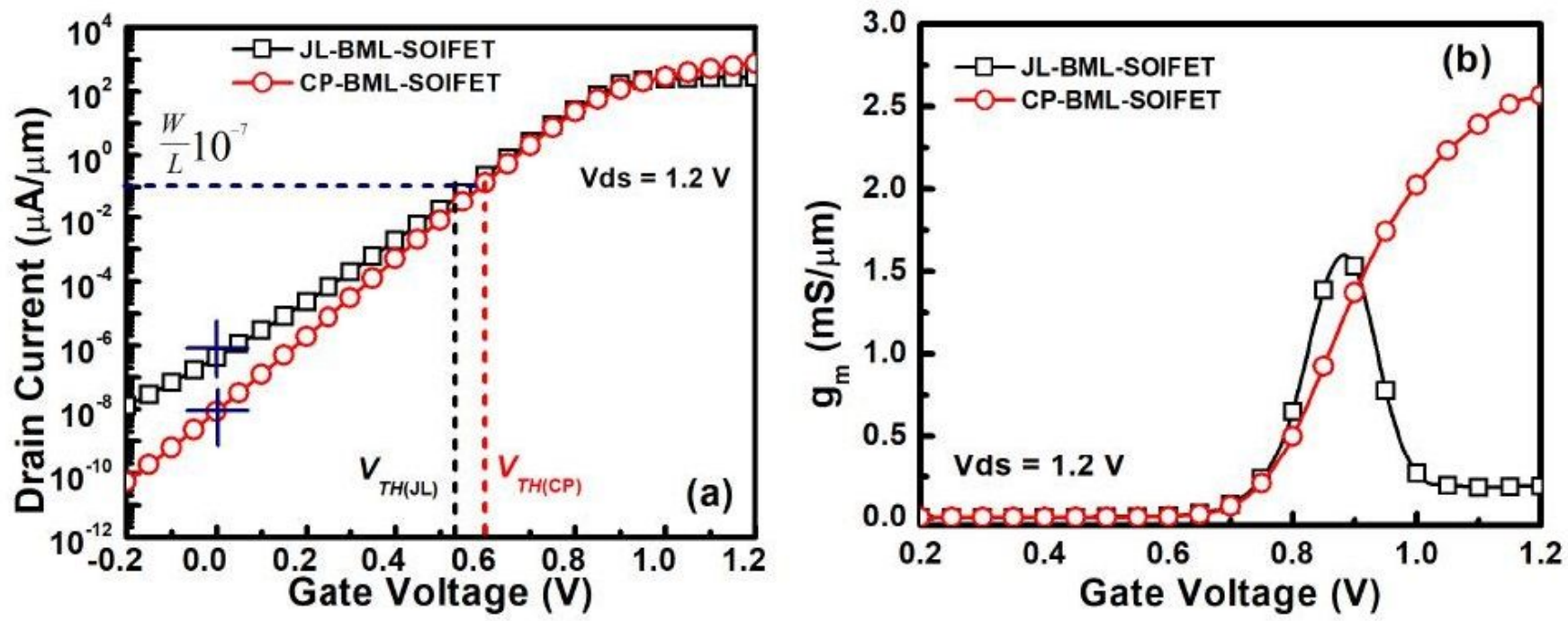

Figure 3

(a) Transfer characteristics for JL-BML FET and CP-BML FET indicating VTh and IOFF at Lg =20 nm. (b) Transconductance characteristics for JL-BML FET and CP囚BML FET at Lg $=20 \mathrm{~nm}$.

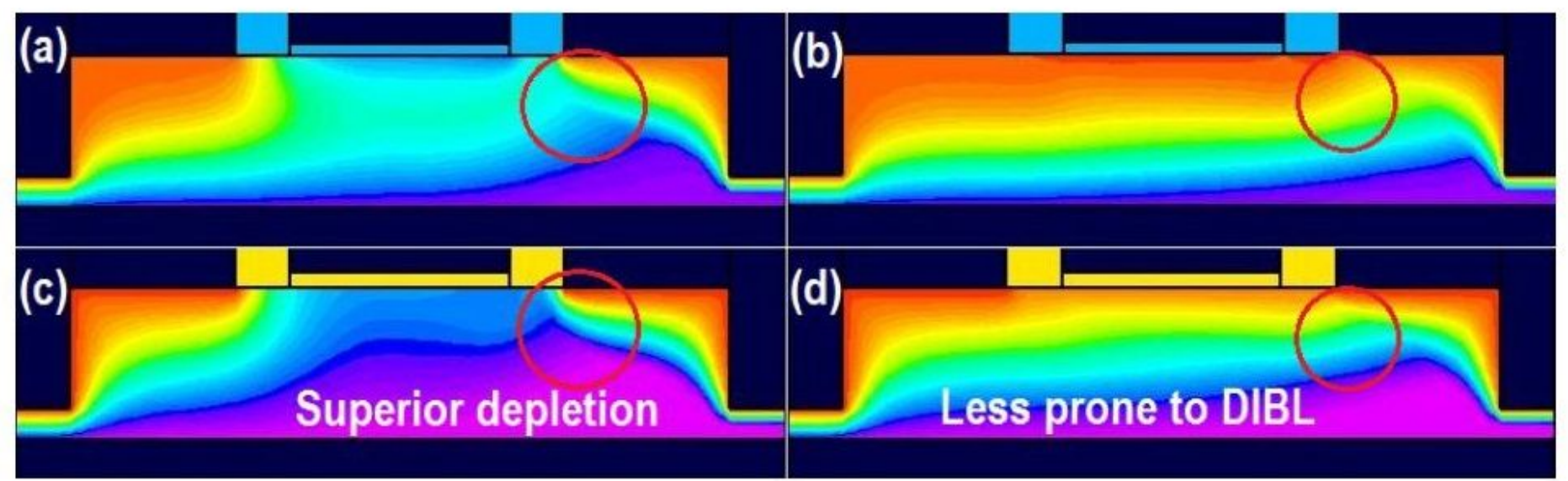

Figure 4

Contour diagrams showing electron concentration for (a) JL-BML FET in OFF state, (b) JL-BML FET in ON state, (c) CP-BML FET in OFF state, (d) CP-BML FET in ON state. 


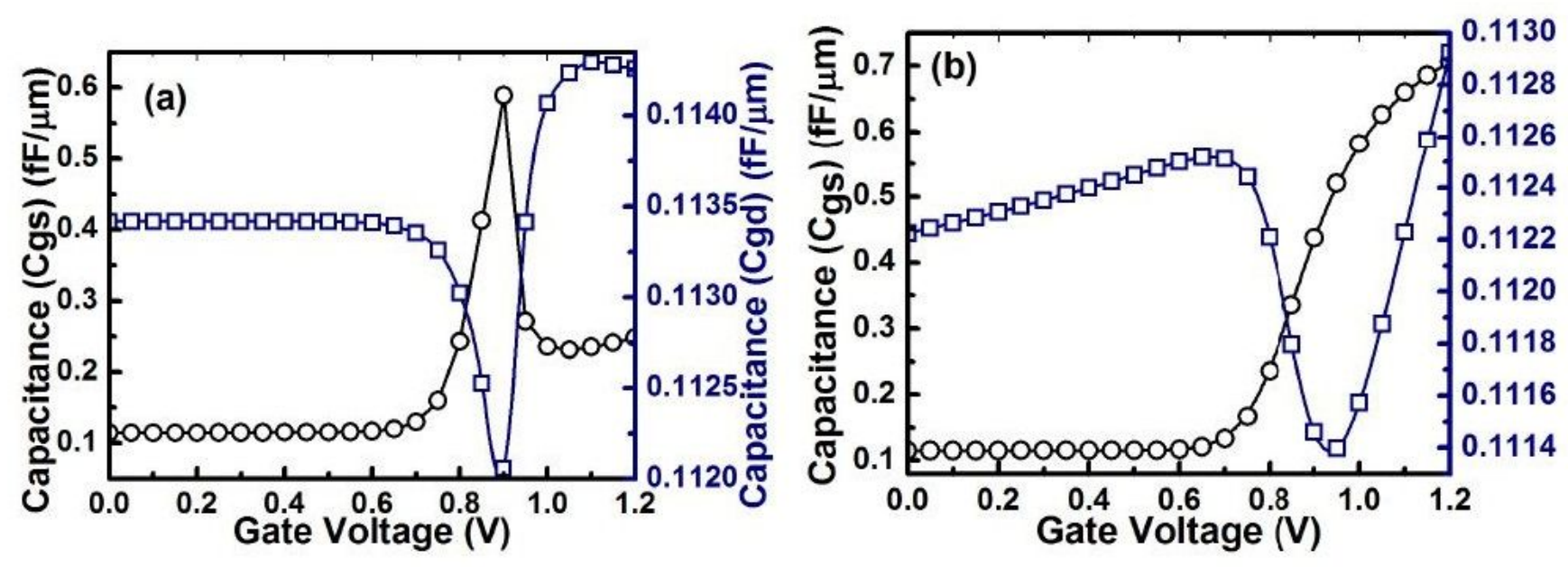

Figure 5

Capacitance (Cgs, Cgd) in different operating regions for (a) Junctionless BML FET (b) Charge Plasma BML FET.
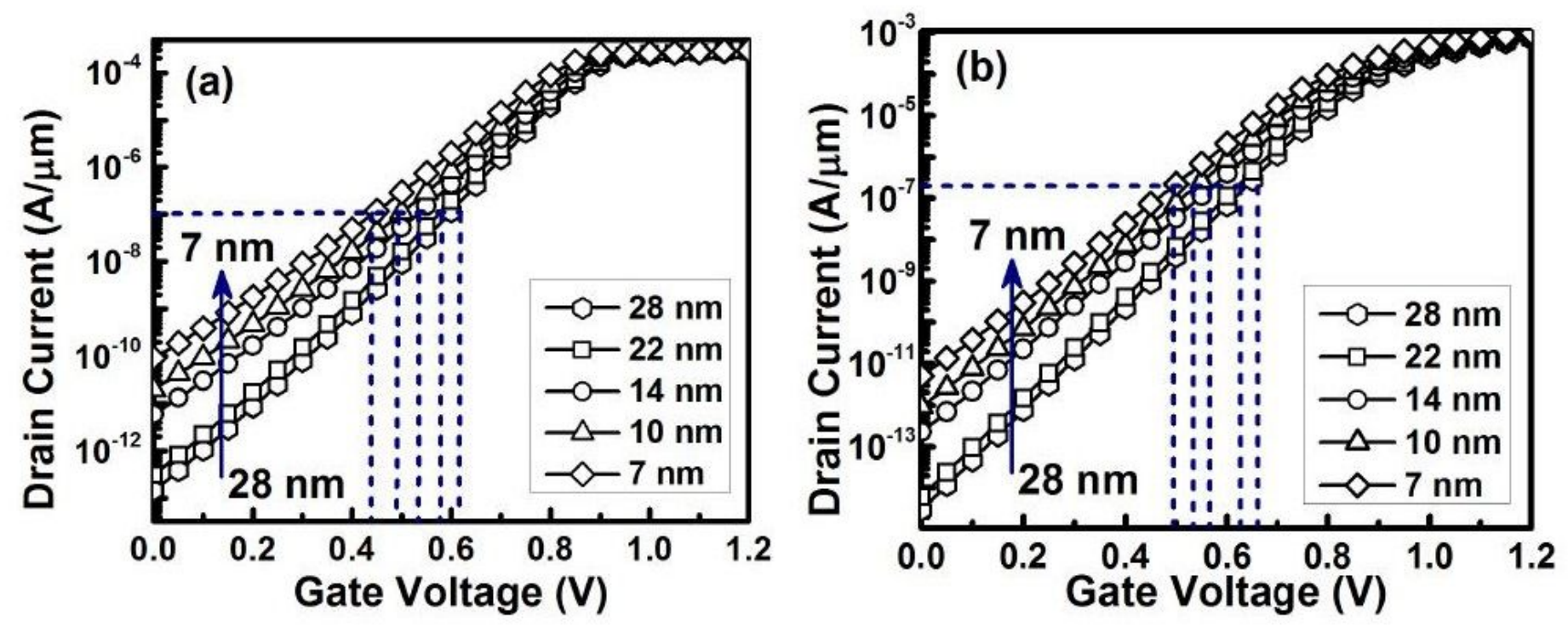

Figure 6

ID vs VGS at varied LG for (a) JL-BML FET (b) CP-BML FET. 

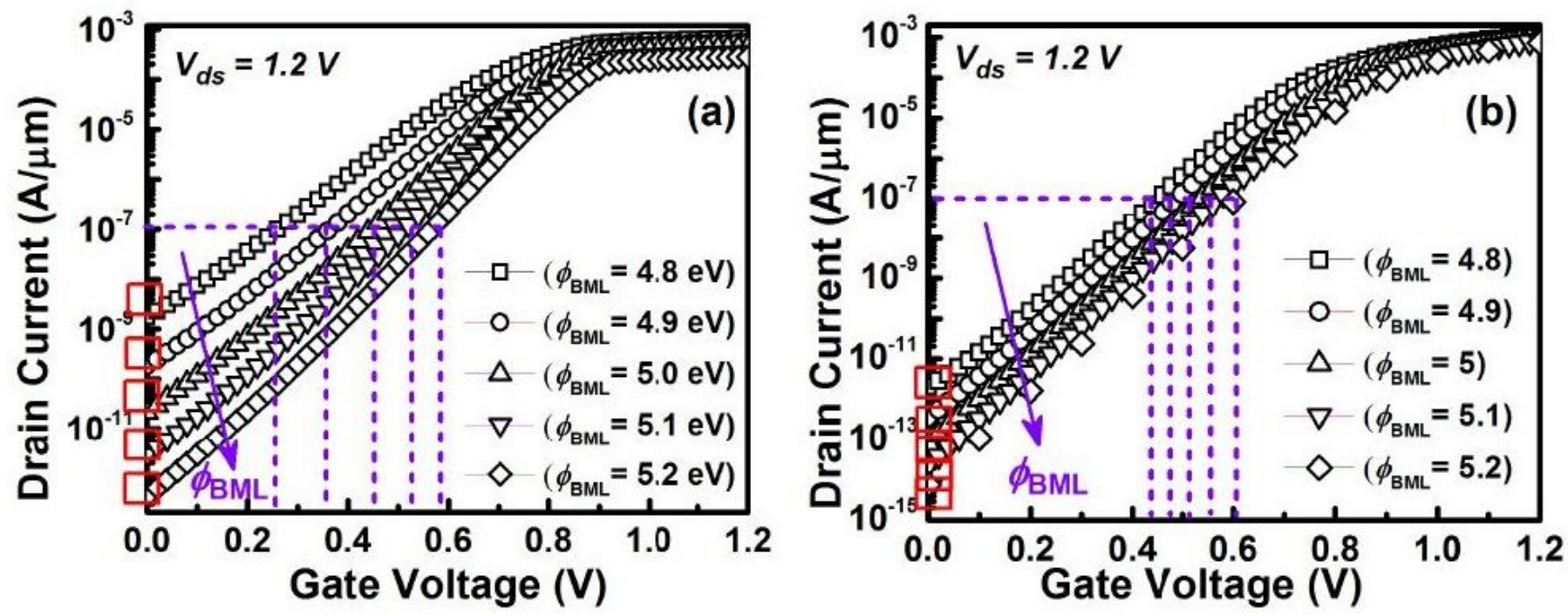

Figure 7

ID-VGS at varied $\varphi B M L$ for (a) JL-BML FET (b) CP-BML FET.
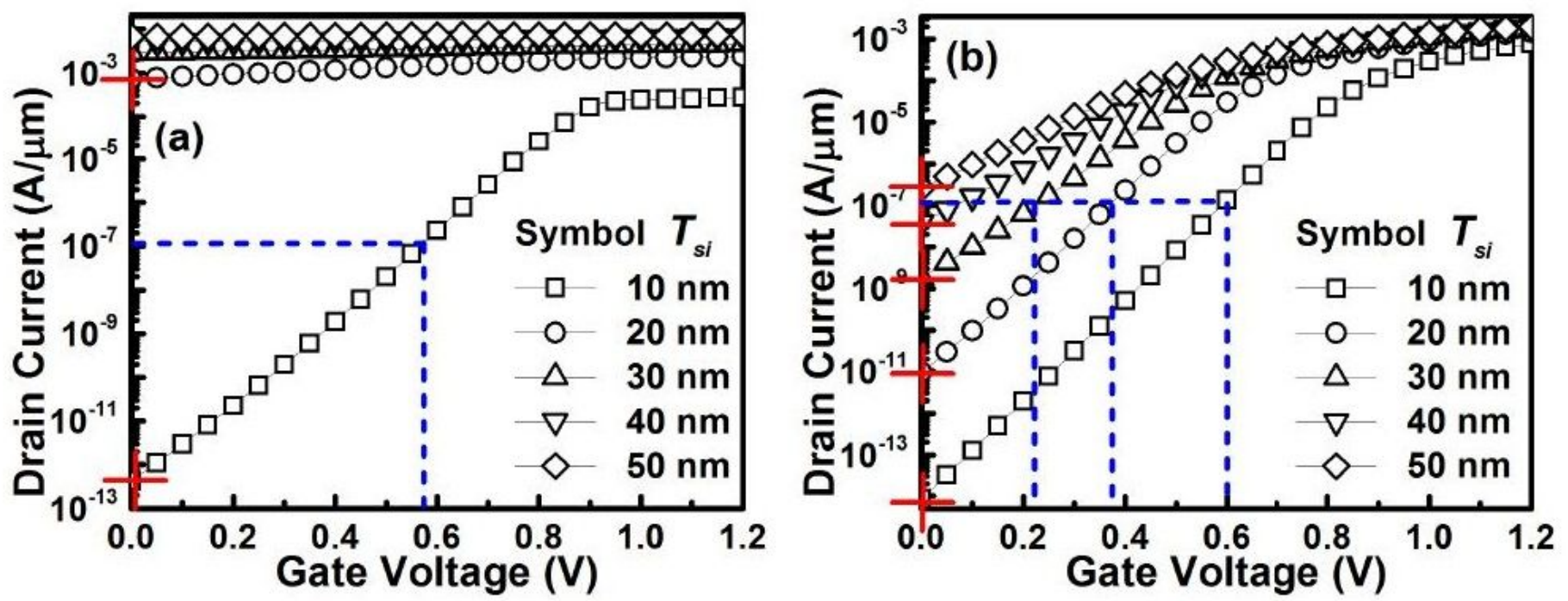

Figure 8

ID vs VGS at varied tSi for (a) JL-BML FET (b) CP-BML FET.
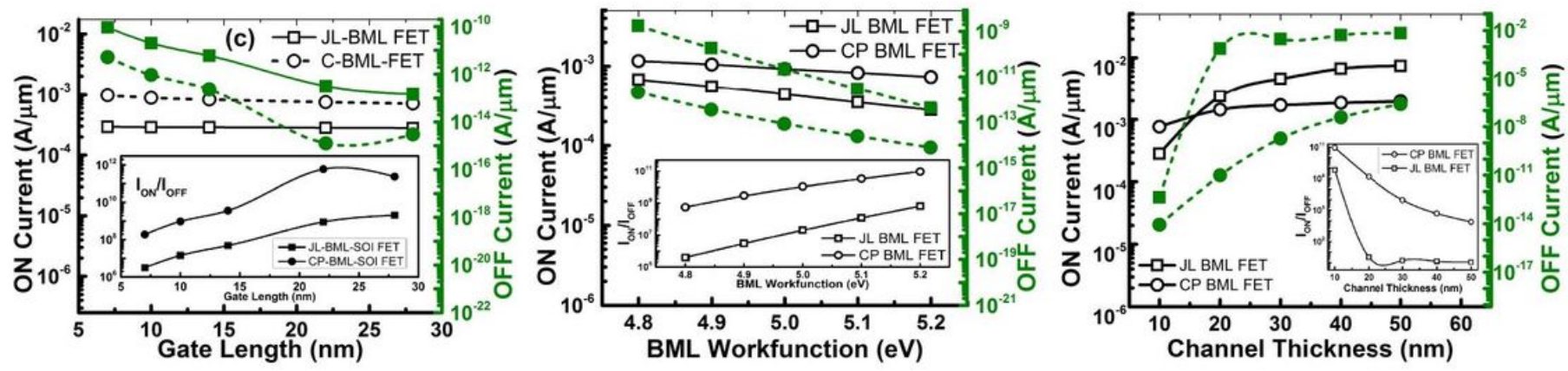
Figure 9

ION, IOFF variations for different (a) LG (b) BML workfunction (c) tSi. Insets shows corresponding ION/IOFF variation
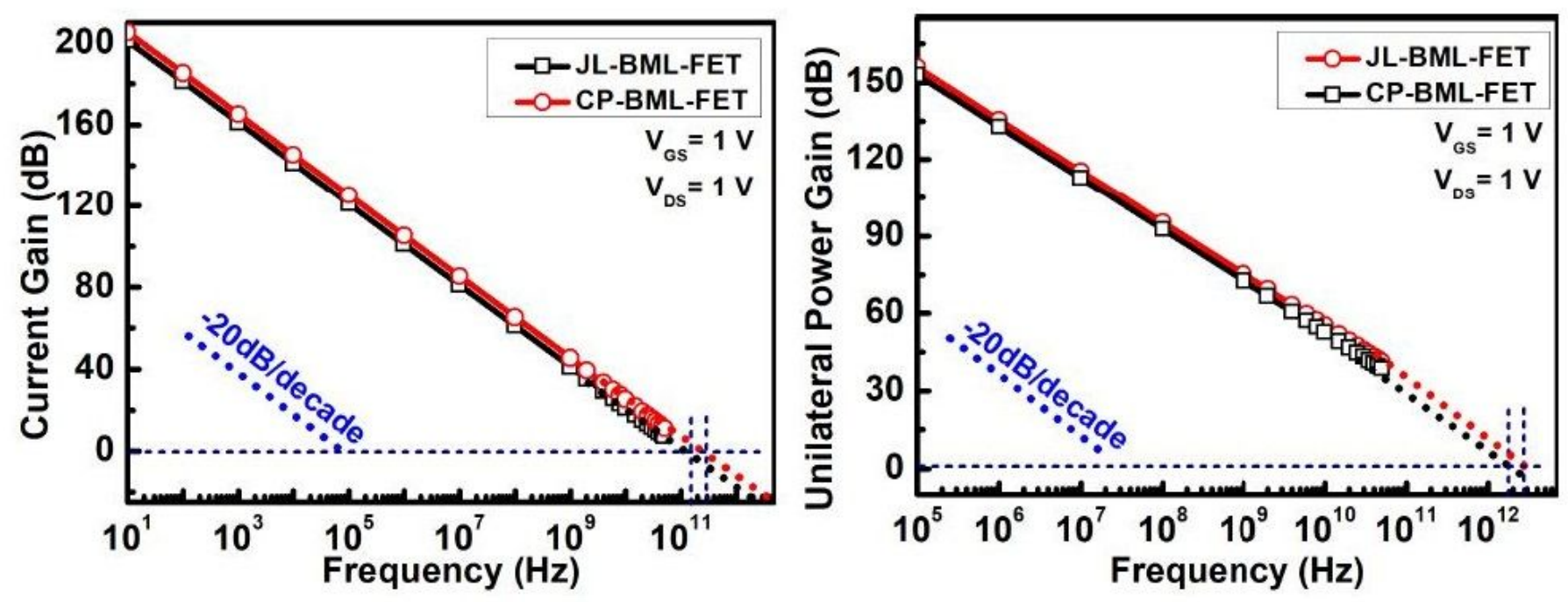

Figure 10

(a) Current gain vs frequency (b) Power gain vs frequency 


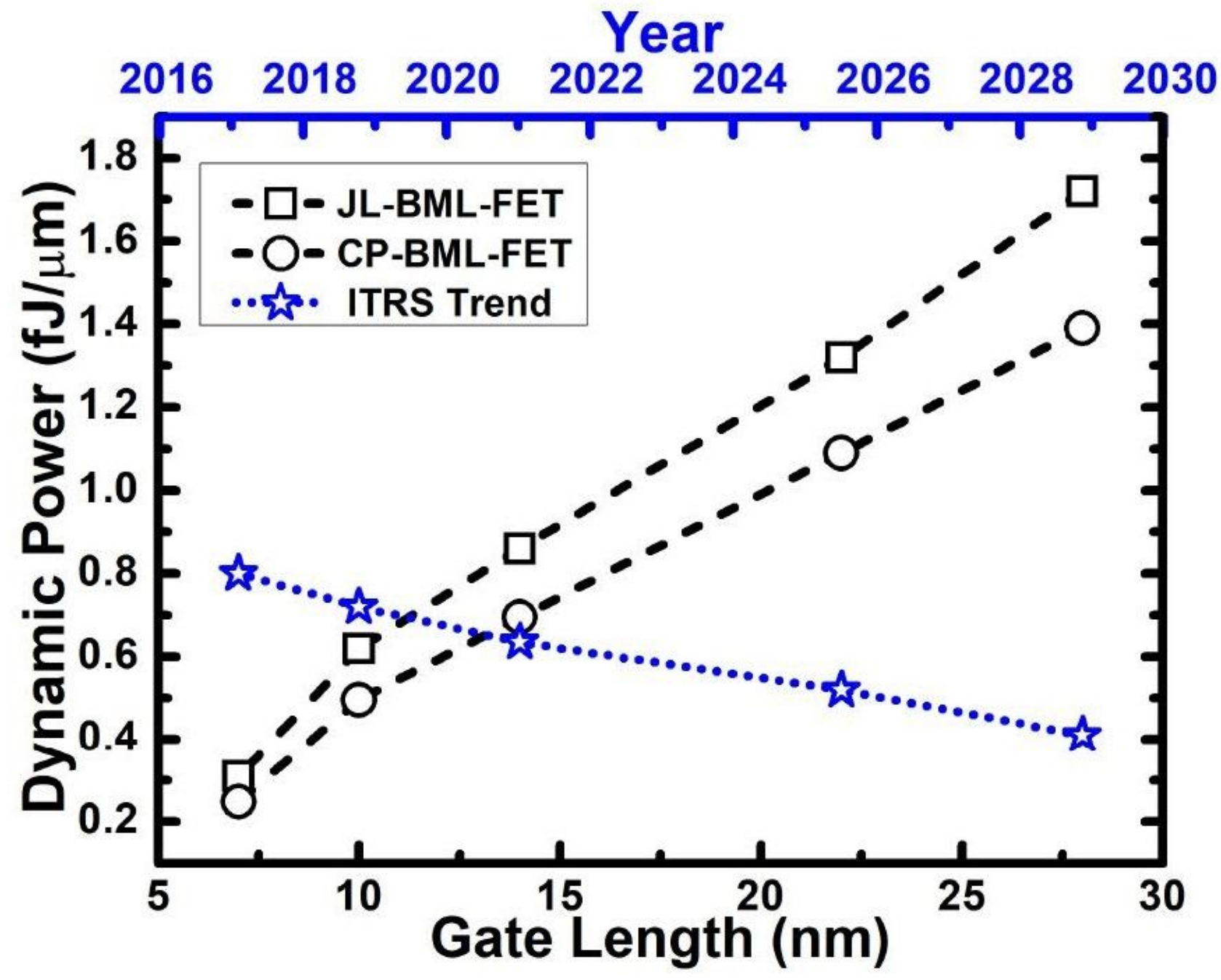

Figure 11

Dynamic power requirement for different LG with ITRS trend. 